\title{
How diverse is child language acquisition?
}

Evan $\operatorname{Kidd}^{1,2,3}$ \& Rowena Garcia ${ }^{1}$

${ }^{1}$ Max Planck Institute for Psycholinguistics.

${ }^{2}$ Research School of Psychology, The Australian National University.

${ }^{3}$ ARC Centre of Excellence for the Dynamics of Language.

\section{Address for correspondence:}

Evan Kidd

Language Development Department

Max Planck Institute for Psycholinguistics

P.O. Box 310 6500XD

Nijmegen, Netherlands.

Email: evan.kidd@mpi.nl

https://orcid.org/0000-0003-4301-2290

Acknowledgements: We thank Adam Usher, Marina Koleva, Jefta Lagerwerf, and Inge Stok for help in coding the data, Jens Roeser and Seamus Donnelly for statistical advice, and Rachel Nordlinger, Nick Evans, Barbara Kelly, Birgit Hellwig, and Caroline Rowland for helpful comments. The research was supported by the Max Planck Society and the Australian Research Council (CE140100041). 


\begin{abstract}
A comprehensive theory of child language acquisition requires an evidential base that is representative of the typological diversity present in the world's 7,000 or so languages. However, languages are dying at an alarming rate, and the next 50 years represents the last chance we have to document acquisition in approximately half of them. In the current paper we take stock of the last 45 years of research published in the four main child language acquisition journals: Journal of Child Language, First Language, Language Acquisition, and Language Learning and Development. We coded each article for the following variables: (i) language(s), (ii) topic(s), and (iii) country of author affiliation, from each journal's inception until the end of 2020. We found that we have at least one article published on around 103 languages, representing only around $1.5 \%$ of the world's languages. The distribution of articles was highly skewed towards English and other well-studied Indo-European languages, with the majority published on non-Indo-European languages having just one paper. There was a more even distribution of topics across language categories, but a vast majority of the research was produced in the Global North. The number of articles published on non-IndoEuropean languages from countries outside of North America and Europe is increasing; however, this increase is driven by research conducted in relatively wealthy countries. We conclude that, despite a proud history of crosslinguistic research, the goals of the discipline need to be recalibrated before we can lay claim to truly a representative account of child language acquisition.
\end{abstract}


On current best estimates, there are approximately 7,000 languages currently spoken today (Eberhard, Simons, \& Fenning, 2021). A key feature of natural languages is their vast diversity, which is evident at every level of analysis (Evans \& Levinson, 2009). At the same time, languages are dying at an alarming rate (Evans, 2010), and the numbers are worrying. Work by Campbell et al. (2013) and Seifart, Evans, Hammarstöm, \& Levinson (2018) shows that over 3,000 languages are moribund, endangered, or nearly extinct. Almost 50\% of the world's languages are projected to be lost by the end of this century, with one language dying, on average, every three months. In our recent history as a species, we have evidence for the loss of 100 language families (out of an estimate of around 420, Campbell et al., 2013). The overall effect is that the world is rapidly losing linguistic diversity at rates greater than biodiversity loss (Seifart et al., 2018; United Nations Intergovernmental Science-Policy Platform on Biodiversity and Ecosystems Services, 2019).

Such rapid language loss has serious implications. First and foremost, each death is a tragedy for the cultural groups who lose their language. Language plays an integral role in the lives of humans; the loss of language has profound human cost because it is through language that we encode and transmit cultural and intellectual knowledge (Evans, 2010; Holtgraves \& Kashima, 2008; Vygotsky, 1962), or as Hale (1992) puts it, "the priceless products of human mental industry" (p. 36). Language also asserts our social identity as members of a particular culture or cultures (Giles, Coupland, \& Coupland, 1991; Gallois, Ogay, \& Giles, 2005), and in minority groups who have managed to preserve their language in the face of colonialism, is linked to higher wellbeing (Hallett, Chandler, \& Lalonde, 2007). Language loss also represents a significant loss for our science: in scientific terms, every language death represents a lost opportunity to understand the boundaries of diversity in the human language faculty. This point cannot be emphasised more: the still waters of language diversity run deep (e.g., see Box 1 in Evans \& Levinson, 2009). A comprehensive theory of any language 
phenomenon requires a representative sample that provides a solid foundation for theory building, and an even bigger sample for theory testing. As more and more languages disappear, we rapidly lose opportunities to better understand our object of study.

Language coverage across the sub-disciplines of the language sciences has been historically uneven. Reviewing progress in the field of language documentation (which emerged as a response to rapid rates of language loss, Hale et al., 1992; Himmelmann, 1998), Seifart et al. (2018) reported that we have basic word lists for around $89 \%$ of the world's languages, and a grammatical description of some sort for around $60 \%$, but that further effort to improve language coverage is needed because work on understudied languages continues to expand the hypothesis space of what is possible in natural language. ${ }^{1}$ Indeed, instead of resulting in diminishing returns, the concentrated focus on documentation over the last 30 years has resulted in a rich new picture of what is possible in language, such that "the documentation of linguistic diversity keeps turning up new phenomena that had either been considered impossible or simply had not been contemplated as linguistic categories" (Seifart et al., 2018, pp. e328 - e329).

Although we are similarly bound to account for language diversity, psycholinguistics has a comparatively poor record in studying diverse languages: Jaeger and Norcliffe (2009) reported that adult language production studies have covered only $0.6 \%$ of the world's languages. In a wider analysis, Anand et al. (2011) reported that $85 \%$ of adult psycholinguistic studies were based on only 10 languages (30\% of which were on English). There has been no past comprehensive study of the number of languages studied in the field of child language acquisition. However, there have been a few past estimates of the degree of language coverage in the field. Lieven and Stoll (2009) estimated that we have child language

\footnotetext{
${ }^{1}$ Note that word lists and grammatical descriptions are only two of many outcomes of language documentation work, which seeks to produce a range of materials on endangered and understudied languages.
} 
data for approximately $70-80$ of the world's languages (approx. 1\%). In a retrospective look at articles published in the Journal of Child Language between 1974 - 2013, Slobin (2014, see also Slobin, 1992, and Crystal, 2014) ${ }^{2}$ reported that the journal had published at least one article on 61 different languages. This figure, however, was skewed: 27/61 (44.3\%) were from the Indo-European family, with the remainder coming from different language families and regions. There were several notable features of these skewed data: while more than half of the languages reported came from outside of the Indo-European family, a striking $1240 / 1425(87 \%)$ of the total number of articles in the journal were on Indo-European languages, with most of those articles dealing the acquisition of English (975/1235, 78.9\%). Thus, English made up 975/1425 $=68.4 \%$ of the entire published work of the journal in its first 40 years, although there was an encouraging downward trend, where the proportion of articles devote to English had steadily declined across time. This downward trend was complemented by a linear trend in the number of articles on new languages increasing. Overall, while there is some degree of typological diversity in the published archives of the field's longest standing journal, we know very little about languages outside of the IndoEuropean family. In fact, apart from a handful of languages that had ten or more articles (Cantonese, Hebrew, Korean, Japanese, Mandarin, \& Tamil), most non-Indo-European languages had only a few, with the modal number being one. A similar though smaller analysis by Kelly and Nordlinger (2014) showed similar results.

It is important to consider what is at stake here. Our field has a justifiably proud tradition of crosslinguistic work, as is most prominent in Dan Slobin's (1985 - 1997) Crosslinguistic Study of Language Acquisition series and in other landmark projects like Berman and Slobin's (1994) crosslinguistic ‘frog story’ narrative project and MacWhinney and Bates' (1989) Crosslinguistic Study of Sentence Processing (for overviews see Bavin,

\footnotetext{
${ }^{2}$ Crystal (2014) reports slightly different numbers to Slobin (2014), but the trends are the same.
} 
1995; Berman, 2014; Bowerman, 2011; Lieven, 1994; Lieven \& Stoll, 2009). The Child Language Data Exchange System (CHILDES, MacWhinney, 2000), which pioneered data archiving and sharing, currently has naturalistic or semi-naturalistic data for 45 languages across its monolingual and multilingual corpora (approximately 53\% of which are IndoEuropean languages) $)^{3}$. The goal of crosslinguistic research is to identify universal and language-specific components of language acquisition (Slobin, 1973, 1985; Slobin \& Bowerman, 2007). Insofar as language documentation research continues to extend the boundaries of what languages can do, it would seem that we should pay attention to a wider array of languages to avoid making errors regarding what might be universal. In casting the widest possible net, we, in words of Bowerman (2011), "guard against parochial explanations of language acquisition" and move "towards theories that do justice to language diversity" (p. 616). Otherwise, we run the risk of making incorrect generalisations on the basis of a limited and skewed dataset.

A casual look back over some past theoretical debates in the field has shown that work on lesser-studied languages has had a profound impact on theory testing and development. Work on child-directed speech in languages like Kaluli, Samoan, and Ki'che' challenged and ultimately falsified the assumption that the prosodic and grammatical modifications observed in 'motherese' in languages like English, German, and French were a universal component of the child's input (Bernstein-Ratner \& Pye, 1984; Ochs \& Schieffelin, 1984; Pye, 1986; see also Ingram, 1989). Work on Ki'che' (Pye \& Quixtan Poz, 1988), Zulu (Suzman, 1987), Sesotho (Demuth, 1989), Inuktitut (Allen \& Crago, 1996), and Jakarta Indonesian (Gil, 2006) falsified arguments that passives are late-acquired due to the delayed maturation of components of Universal Grammar (Borer \& Wexler, 1987). Work on ergative languages questioned the utility Pinker's $(1984,1989)$ innate linking rules, and the inherent

\footnotetext{
${ }^{3}$ This figure was computed on September 4, 2021.
} 
complexity and variability in ergative marking across languages questioned the likelihood they could be described by parameter-setting approaches (Pye, 1990; Van Valin, 1992; see also papers in Bavin \& Stoll, 2013). The graveyard of child language theory past is populated by the handiwork of crosslinguistic assassins.

Other crosslinguistic work has served as a testing ground for theory testing and refinement. Cross-cultural studies of children's linguistic environment continue to expand the types of conditions under which children are socialised into language (Brown, 2012; Casillas, Brown, \& Levinson, 2020; de León, 2012; Ochs \& Schieffelin, 2012). Work on highly inflected languages has challenged theoretical approaches to morphological acquisition that postulate the use of abstract rules (Marcus et al., 1992; Pinker, 1994), and instead provide evidence in favour of schema-based generalisations (e.g., Dabrowska, \& Szczerbinski, 2006; Engelmann et al., 2019; Forshaw, 2021; Granlund et al., 2019). Our own work on children's processing in languages like Cantonese, Mandarin, and Tagalog has shown that online parsing choices are intimately tied to input frequency (e.g., Chan, Yang, Chang, \& Kidd, 2018; Garcia, Garrido Rodrigues, \& Kidd, 2021; Yang, Chan, Chang, \& Kidd, 2020), and cannot be explained solely with reference to abstract, language-independent grammatical principles. In terms of contribution, when we ask the right questions of them, research on lesser-studied and typologically-diverse languages can move us forward at a faster rate than work on typically-studied European languages.

The predominantly Indo-European bias in our research raises other questions about diversity in our discipline concerning the producers of our canon of knowledge. As a discipline child language acquisition spans the fields of linguistics and developmental psychology, and the latter discipline is very much centred in the Global North. Nielsen, Haun, Kärtner, and Legare (2017) reported an analysis of articles published in the topranking developmental psychology journals (Child Development, Developmental Psychology, 
and Developmental Science) between 2006 and 2010, finding that 90.52\% of articles were based on participants drawn from the United States, Europe, or other wealthy Englishspeaking countries (i.e., Australia, Canada, New Zealand, and the United Kingdom). It is fairly safe to assume that the studies were mostly conducted by researchers in those same countries, suggesting that the means of research production is concentrated there. This is not surprising: research in the social sciences and humanities is a privilege afforded to us by wealth. However, if we truly aim to build theories of what it means to be human, we need to ask ourselves whether whole research disciplines that concentrate almost solely on Western Educated, Industrialised, Rich and Democratic societies is an acceptable state of affairs (Heinrich, Heine, \& Norenzayan, 2010). If it is not, then we need to develop ways to decolonise our discipline to make it more accessible to a greater proportion of the world's population (Defina, Allen, Davidson, Hellwig, Kelly, \& Kidd, 2021; Hellwig, Defina, Kidd, Allen, Davidson, \& Kelly, 2021; Pye, 2021).

In the current paper we take stock of the last 45 or so years of modern child language research by analysing the distribution of languages and topics reported in our four main journals (Journal of Child Language, First Language, Language Acquisition, Language Learning and Development) from each journal's inception to the end of 2020. We ask: (i) for how many different languages do we have published articles? (ii) what is the frequency distribution of languages across the data and, following Slobin (2014), has this changed across time? (iii) what is the frequency distribution of topics studied in the field, and does this vary by language category and over time? and (iv) who are the producers of our knowledge, and has this changed over time? 


\section{Method}

\section{Inclusion and Exclusion}

We screened all 3,245 articles published in language acquisition journals from their initial issue until the end of 2020: Journal of Child Language (JCL, from 1974: 1809 articles), First Language (FL, from 1980: 696), Language Acquisition (LA, 1990: 422), and Language Learning and Development (LLD, 2005: 318). We excluded a total of 418 articles that did not report primary data on child language acquisition (164 LA, 125 LLD, 96 JCL, 33 FL). Reasons for exclusion included: theoretical article, methodological article, book review, computational modelling article, editorial, introduction, commentary, reply, correction/errata, memorial, acknowledgement, dissertation announcement, reprint, insufficient information on data (e.g., anecdotal reports of children's productions), only adult or non-human data, children's real language skills not tested (e.g., artificial grammar learning study, non-word repetition), and reanalysis of previously reported data. Overall, 2,827 articles were included in the analyses.

\section{Annotation}

Three research assistants coded each included article on the following dimensions: (i) year of publication, (ii) speaker group type (mono- versus multilingual), (iii) languages studied (including the language family), (iv) topic/s studied, and (v) country of the authors' affiliations.

\section{Speaker group}

Each article was coded for whether its participants were monolingual, multilingual, or both. For studies of child-directed speech, we coded the adults' speaker group type. This variable thus reveals the degree to which articles in the four journals focus on monolingual or multilingual development. This information was typically gleaned from the participants section of the article; however, not every author explicitly reported whether their participants 
were mono- or multilingual. In these cases, coders scrutinised the article further to find evidence that would allow a categorisation. If no further evidence was present, it was coded as 'Not Reported'.

\section{Language}

Only the language(s) that the study's participants knew and had been tested on were coded. If the participants were tested on an existing language that was unfamiliar to them (e.g., when English-speaking children were tested in Hindi phonemic contrasts, or participants were tested on an artificial language), the article was excluded because the study did not directly test the acquisition of the children's input language. Similarly, if a multilingual group was tested on only one of their languages, only the language that was tested was coded.

Coding languages always results in dilemmas regarding the vague distinction between language and dialect. This issue occurred a few times in the dataset. Sometimes there were historical reasons for different language names. For instance, there were articles reporting data on both Serbian and Serbo-Croatian; the difference in language name reflecting geopolitical changes following the dissolution of the former Yugoslavia. We coded these articles as 'Serbo-Croatian', which is accepted by Slavic linguists and captures the fact that the regional varieties comprise a polycentric language group. ${ }^{4}$ Whenever there were issues in categorizing language varieties, we consulted the authors of the articles, as well as other experts to come up with a decision. For example, after consultation with authors we also decided to label the different varieties of Arabic as a polycentric language, under the broad term 'Arabic'. We did the same for different varieties of English, Spanish, German, and Greek. However, we coded articles reporting on Quechua into two varieties: Conchucos

\footnotetext{
${ }^{4}$ In 2017 the Declaration of the Common Language was issued by 200 individuals, having been drafted by experts, half of whom included linguists. It states that individuals in Bosnia and Herzegovina, Croatia, Montenegro, and Serbia have a common polycentric language. For more details see: https://en.wikipedia.org/wiki/Declaration on the Common Language
} 
Quechua and Southern Peruvian Quechua, based on the typological work on the family (Torero, 1974). All sign languages were coded as separate languages.

No doubt some of these decisions would not please speakers of regional varieties (or sociolinguists). Some big languages exhibit greater variation within varieties than others (e.g., Arabic has been argued to have the same diversity as the Romance language family, Holes, 2004, although Modern Standard Arabic exists as a spoken register and literary standard). Our decisions tend to err on the side of conservatism. However, we note that even if we did count all dialects as separate languages it would only minimally change the estimate of language coverage.

Language family of spoken languages was coded using Ethnologue (Eberhard et al., 2021). While there have been recent efforts to establish a phylogeny of signed languages (e.g., Power, Grimm, \& List, 2020), the topic is not without controversy (Chloe Marshall, p.c., 7/7/21). We avoid making arbitrary decisions here and place signed languages into one theory-neutral category. Creoles and mixed languages (e.g., Light Warlpiri) were also placed into one category.

Topic. The articles were coded as having one or more of the following topics: Speech, Morphosyntax, Vocabulary and Semantics, Pragmatics and Discourse, Language and Cognition, and Non-verbal communication. The Speech category included studies of phonology, phonetics, and prosody. Studies of grammatical relations were labelled Morphosyntax. Vocabulary and Semantics included studies investigating the acquisition of words and meaning (at the lexical level). Pragmatics and Discourse included studies investigating the acquisition of communicative intent, speech acts, conversation, and narrative production and comprehension..$^{5}$ Language and Cognition included studies focusing

\footnotetext{
${ }^{5}$ Originally the Vocabulary, Semantics, Pragmatics, and Discourse were four independent categories, but coders had trouble agreeing on the distinction between Vocabulary and Semantics, on the one hand, and Pragmatics and Discourse, on the other. We thus merged them. It was encouraging to see that the difficulties lay at where one would expect the boundaries to be most porous.
} 
on reading / literacy, metalinguistic ability, and the interface between language and broader human cognitive processes (e.g., language and emotion). Non-verbal communication included studies investigating gestures and other communicative acts (e.g., eye gaze).

These categories are broad, but the nature of research is that it was not always easy to neatly place an article in only one. Therefore, coders were encouraged to list as many as codes as were relevant. Most of the articles were categorized using one to two topics.

Country of author. We coded the country of the affiliation of each article's authors. If an article had authors from different universities in one country, this country was counted only once. The same was done whenever the different authors of the article were from the same university. Thus, if an article had three authors, two from the United States and one from Spain, it counted as having contributions from those two countries, only counting the United States once. This variable is intended to estimate the locus of research production. The regions were assigned following the United Nations Statistics Division's (2021) M49 Standard.$^{6}$

Coding and reliability checks. To check for inter-rater reliability, we pseudorandomly selected 228 articles (7\%) so that there was a representative number of topics covered. These were re-coded by a new coder, blind to the original coding, based on the following: inclusion or exclusion, languages, topic/s, and speaker group type (country of author was straightforward and did not need to be assessed). Given that an article could have more than one topic assigned to it, the reliability for this feature of the data calculated the degree to which two coders identified at least one matching topic.

The Cohen's kappa scores for the different dimensions annotated by Coder 1 and 2 were all above 0.90 (inclusion: 0.94 , language: 0.98 , at least one matching topic: 0.91 ,

\footnotetext{
${ }^{6}$ https://unstats.un.org/unsd/methodology/m49/\#geo-regions
} 
speaker group type: 0.96), indicating almost perfect agreement between the coders. Coder 3's annotations were re-coded by the second author, with the Cohen's kappa scores also indicating almost perfect agreement (inclusion: 1.0, language: 1.0, at least one similar topic: 0.97, speaker group type: 0.95 ).

\section{Analysis}

All analyses were conducted in R version 4.0.3 (R Development Core Team, 2016). We calculated the number of articles published in child language journals per year, depending on the language, language group (English, other Indo-European languages, nonIndo-European languages, see below), topic, as well as the countries and regions of affiliations of the authors. We also fitted Poisson regression models on the data, to analyse whether the distribution of the articles changed across time. For this, we used the $g l m$ and predict functions of the lme4 package (version 1.1-26, Bates et al., 2015). Model fit was determined using the aictab function of the AICcmodavg package (version 2.3-1, Mazerolle, 2020) and base R's anova function. Our data and analysis scripts are available on the Open Science Framework: https://osf.io/jmxnw/.

\section{Results}

\section{Preliminaries}

Of the 2,827 included articles, $61 \%$ were from JCL, $23 \%$ from FL, $9 \%$ from LA, and $7 \%$ from LLD. Table 1 reports the data on the distribution of speaker group types. There were more articles with monolingual participants compared to those with multilingual participants or both. However, $56 \%$ of the articles did not report the speaker status of their sample. We were able to code an additional $14 \%$ of articles by further scrutinising them. In each case these articles reported on monolingual populations, yet this still left $42 \%$ as unclassifiable. Thus, given the greater focus in the journals on monolingual populations, it appears that whether or not a sample is mono- or multilingual is not always explicitly stated, 
and being monolingual is often treated as an unspoken norm. Journal editors should consider requiring authors to explicitly state their recruitment criteria.

\section{Table 1.}

Distribution of Speaker Group Type in Articles Published in Child Language Journals between 1974 and 2020.

\begin{tabular}{lll}
\hline \hline & $\begin{array}{l}\text { Accepting coders' } \\
\text { judgment if it was not }\end{array}$ & $\begin{array}{l}\text { Without accepting coders' } \\
\text { reported (\%) }\end{array}$ \\
& 43 & reported (\%) \\
\hline Monolingual & 8 & 29 \\
Multilingual & 7 & 8 \\
Both & 42 & 7 \\
Not reported & & 56 \\
\hline
\end{tabular}

\section{Languages}

There is at least one article published in child language journals on a total of 103 languages. Thus, assuming that there are 7,000 natural languages, the four major child language journals have published articles on around $1.47 \%$ of them. The number of articles is not evenly distributed across the language families of the world. The majority were on English (54\%). Thirty-eight additional languages came from the Indo-European family, making up 30\%, with the remaining 16\% coming from 64 different languages that belong to 25 different language families. We use these three (i.e., English, other Indo-European, nonIndo-European) as categories in our subsequent analyses. Figure 1 shows the number of articles published in each category over time. Figure 2 shows the frequency distribution of the Indo-European languages, and Figure 3 shows the frequency distribution of the non-IndoEuropean languages (see Appendix A for raw frequencies per language). Figure 1 shows an 
increasing trend in the number of articles published across time, which is characteristic of all language categories.

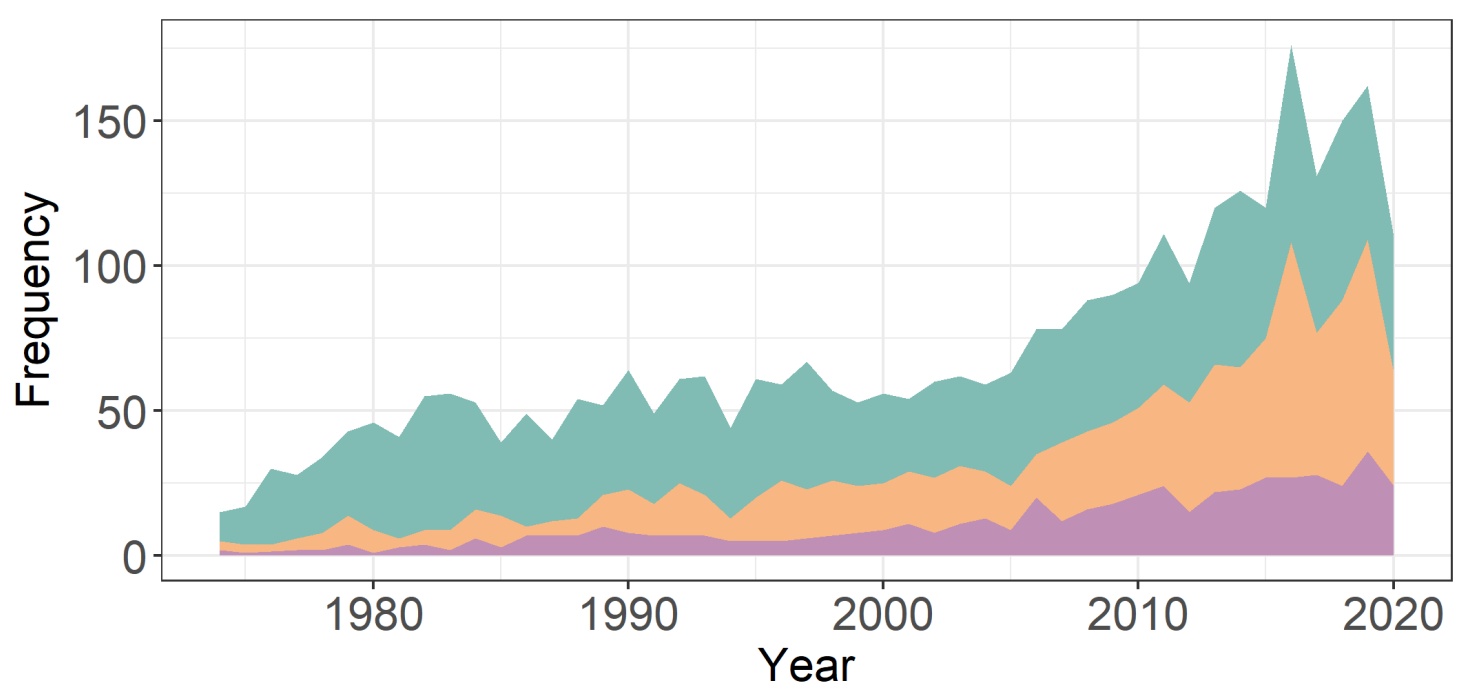

Language English other Indo-European non-Indo-European

Figure 1. Frequency distribution of articles on English, other Indo-European languages, and non-Indo-European languages published in child language journals between 1974 and 2020 .

Figures 2 and 3 show that the frequencies in both the Indo-European family and all other languages is skewed. In the Indo-European category, English and large Romance and Germanic languages have many articles, whereas the number for other languages is much smaller. The same right-skew is observed in the non-Indo-European language category: a few languages had many articles (e.g., Hebrew, Mandarin, Japanese), while the modal number was 1. 


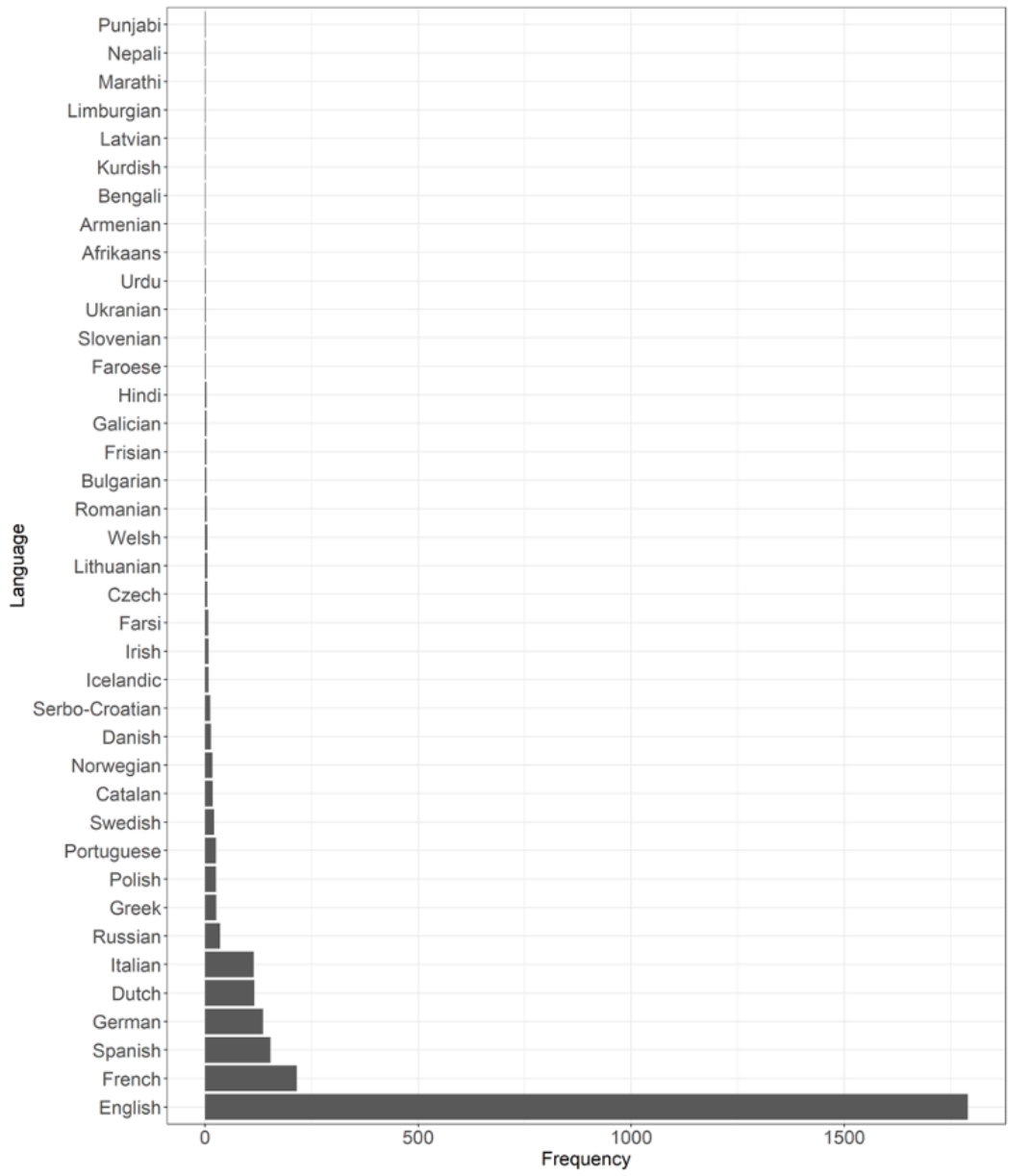

Figure 2. Frequency distribution of articles on Indo-European languages published in child language journals between 1974 and 2020.

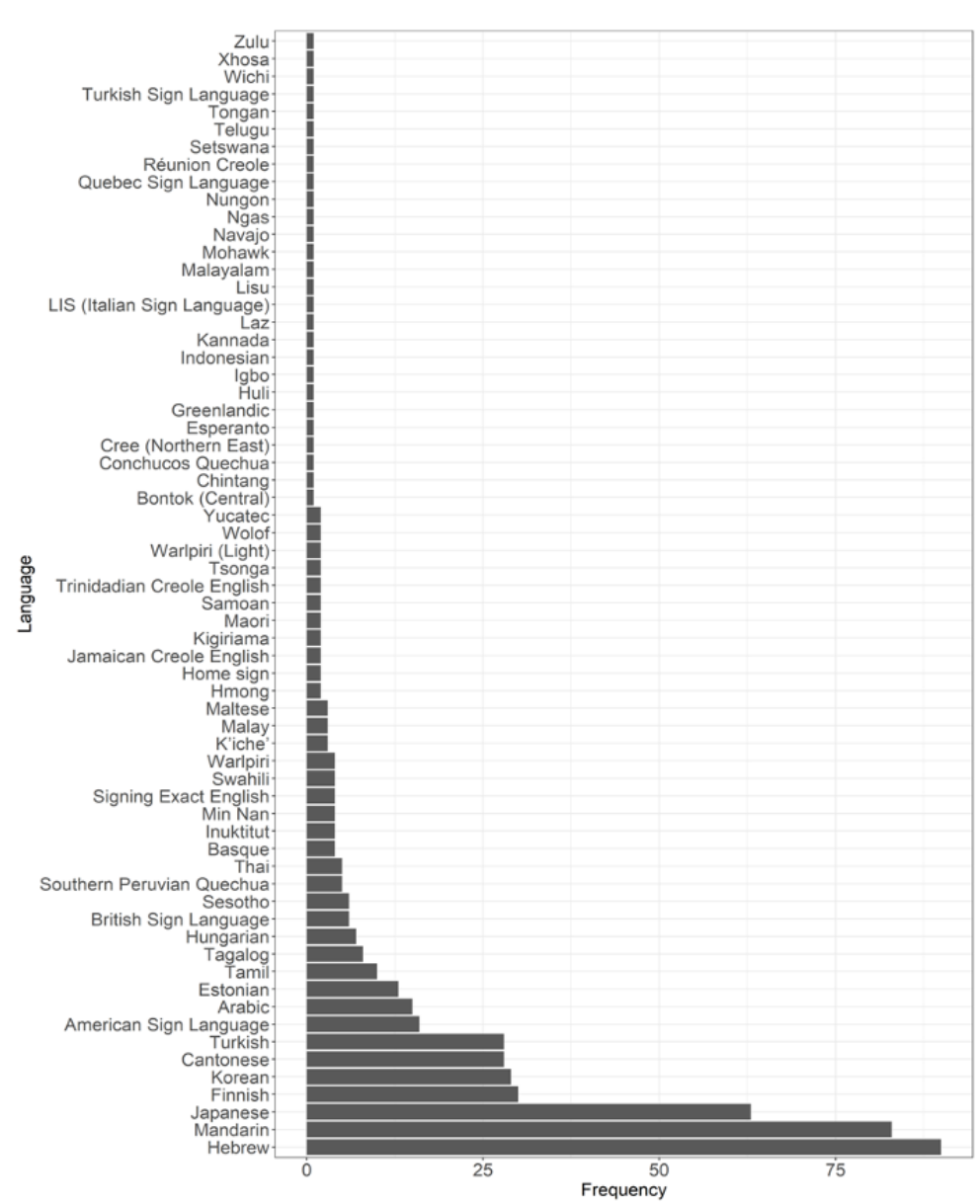

Figure 3. Frequency distribution of articles on non-Indo-European languages published in child language journals between 1974 and 2020. 
In order to investigate whether the distribution of articles across the three language categories changed across time, we fitted a Poisson regression model predicting the number of articles published from language group and year of publication. Language group was a categorical independent variable (English, other Indo-European languages, non-IndoEuropean languages) and was treatment coded: English was selected as the reference level so that the coefficients could be interpreted as to how publication rates in the other two categories differed from the most frequent language overall and across time. Year of publication was adjusted such that the first year (1974) was treated as 0 , and the succeeding years were each year's difference from 1974 (e.g., 1976 as 2). This way, the coefficients in the models refer to the difference between the language groups in the year 1974, instead of in the year $0 \mathrm{AD}$. Year of publication was entered as a continuous independent variable. The best-fitting model included the main effects of language group and time, and the interaction between the two.

The results show significant main effects and interaction of year and language group (see Table 2). To understand the interaction of year and language group, we plotted the predictions of the model with and without the interaction. The model with the interaction shows that the number of articles on English is growing linearly across time, while those on other Indo-European languages and non-Indo-European are growing exponentially (see Figure 4). In other words, in more recent years, the number of articles on languages other than English is growing more rapidly than the number of articles on English. 
Table 2.

Final Regression Models Predicting Number of Articles by Year and Language Group.

\begin{tabular}{lllll}
\hline \hline Predictor & Estimate & SE & $z$ value & $p$ value \\
\hline Intercept & 3.24 & 0.05 & 62.79 & $<.001$ \\
Year & 0.02 & 0.002 & 9.19 & $<.001$ \\
Other Indo-European & -1.92 & 0.11 & -17.33 & $<.001$ \\
Non-Indo-European & -2.45 & 0.14 & -17.10 & $<.001$ \\
Year:Other Indo-European & 0.04 & 0.003 & 13.53 & $<.001$ \\
Year:Non-Indo-European & 0.04 & 0.004 & 9.81 & $<.001$ \\
\hline
\end{tabular}

AIC: 860.77, Log-likelihood: -424.07

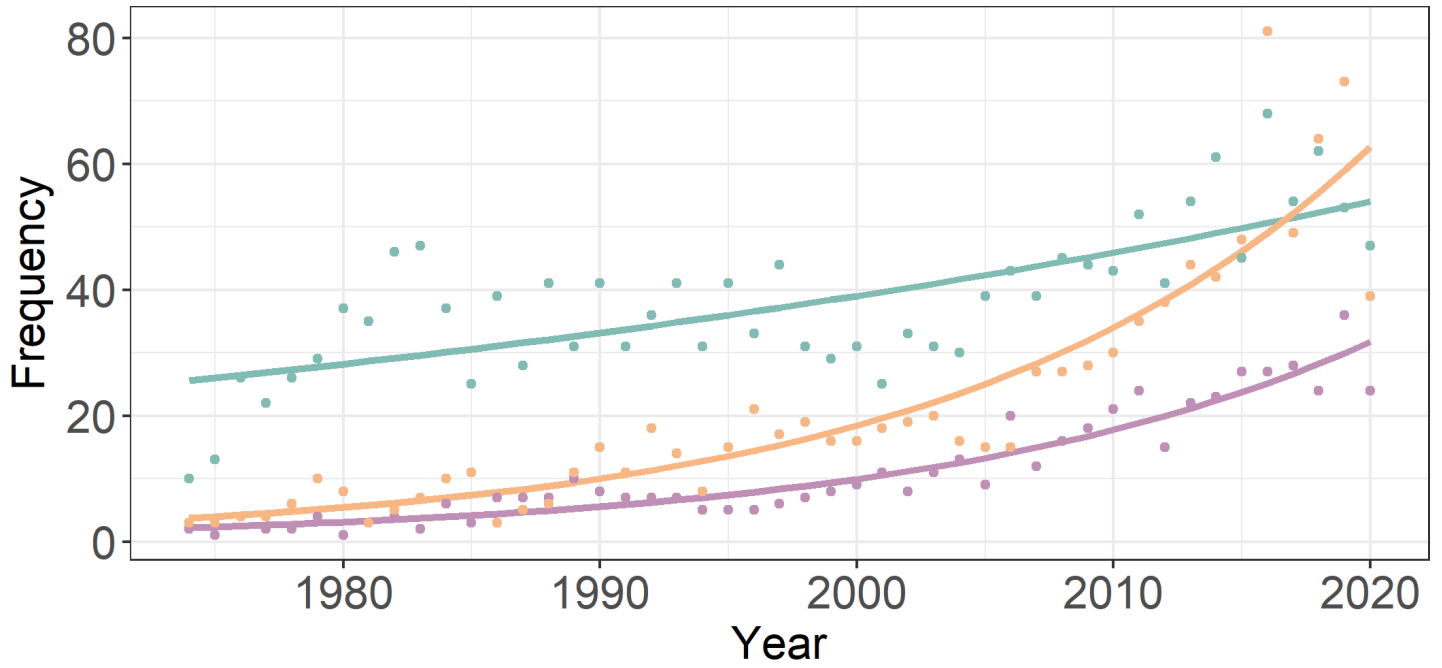

Language $=$ English $=$ other Indo-European $=$ non-Indo-European

Figure 4. The number of articles published on different language groups per year. The dots correspond to the actual number of articles (i.e., the raw data), while the lines correspond to the values predicted by the regression model. 
Given the difference in growth between articles focusing on English versus languages other than English, a reasonable question to ask of the data is: at what point would we expect the two other categories to match English? To answer this question, we computed a regression model on the cumulative number of articles. The best-fit model included the main effects of language group and year, as well as their interaction (see OSF materials for modelling details). Figure 5 plots the model predictions, showing that, on current trends, we can expect the total number of articles in English and other Indo-European languages combined to be equivalent by 2048. That same figure for non-Indo-European languages is 2070. However, it is important to point out that, since the current distributions across IndoEuropean and non-Indo-European languages is severely skewed, these predictions do not mean that coverage will be even by these dates, only that the total number of articles will be equivalent. This means, unless something changes, the languages in each category will be skewed towards well-studied languages like Germanic and Romance languages, in the case of Indo-European, and languages like Hebrew, Japanese, Mandarin, and Finnish, in the case of the non-Indo-European languages.

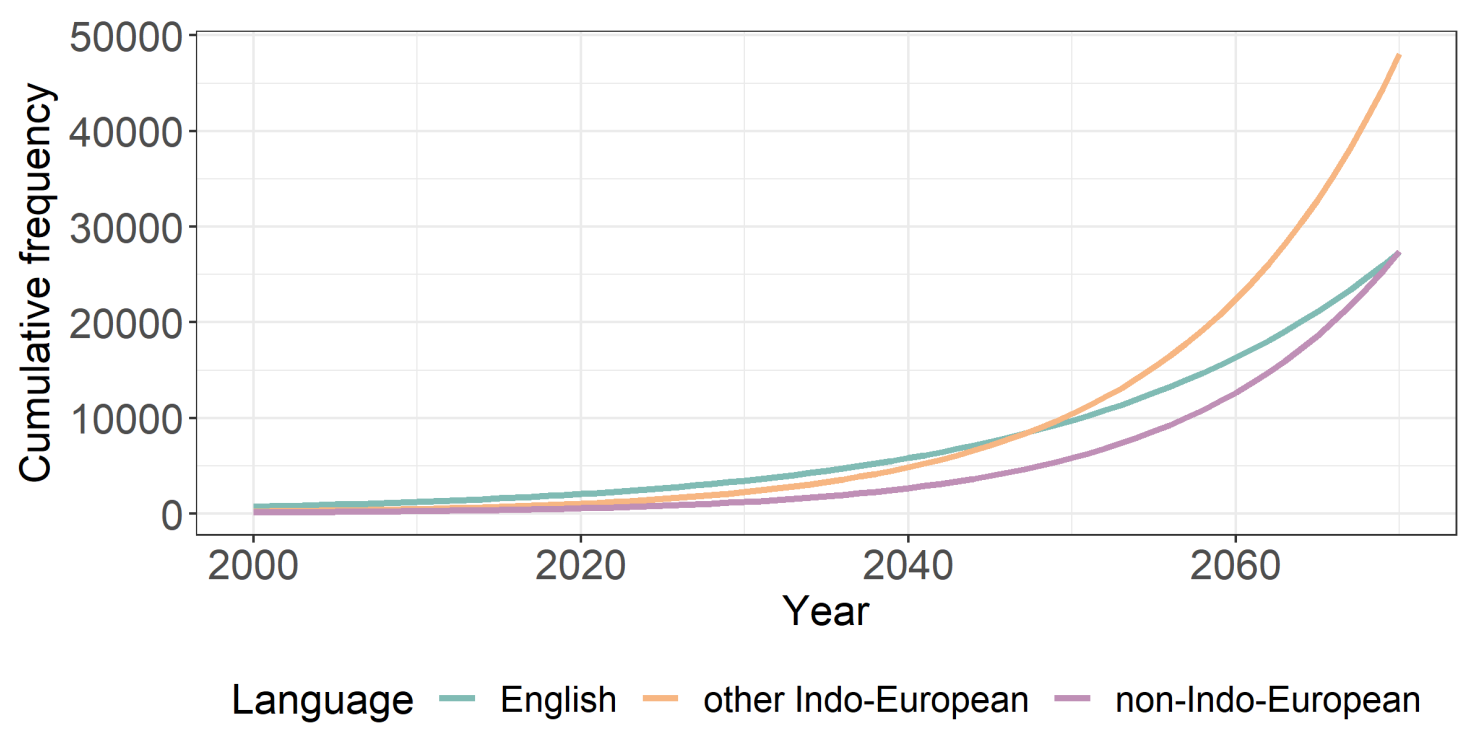

Figure 5. Predicted cumulative number of articles in child language journals per language group, based on the regression model. 


\section{Topics}

Table 3 shows the frequency of each topic across the whole data set. Morphosyntax was the highest, closely followed by Vocabulary and Semantics, which together account for just over half of the data. Non-verbal communication had the fewest number of articles. The topic distribution within the language groups: English, other Indo-European, and non-IndoEuropean languages can be seen on Figure 6, and across time in Figure 7. Figure 6 shows a fairly even overall distribution of topics across the three language categories; Figure 7, like Figure 1, shows a more recent increase in articles published on languages other than English compared to English.

\section{Table 3.}

Distribution of Topics of Articles Published in Child Language Journals between 1974 and 2020.

\begin{tabular}{ll}
\hline \hline Topic & Distribution (\%) \\
\hline Morphosyntax & 27 \\
Vocabulary and Semantics & 24 \\
Pragmatics and Discourse & 19 \\
Language and Cognition & 15 \\
Speech & 12 \\
Non-verbal communication & 3 \\
\hline
\end{tabular}




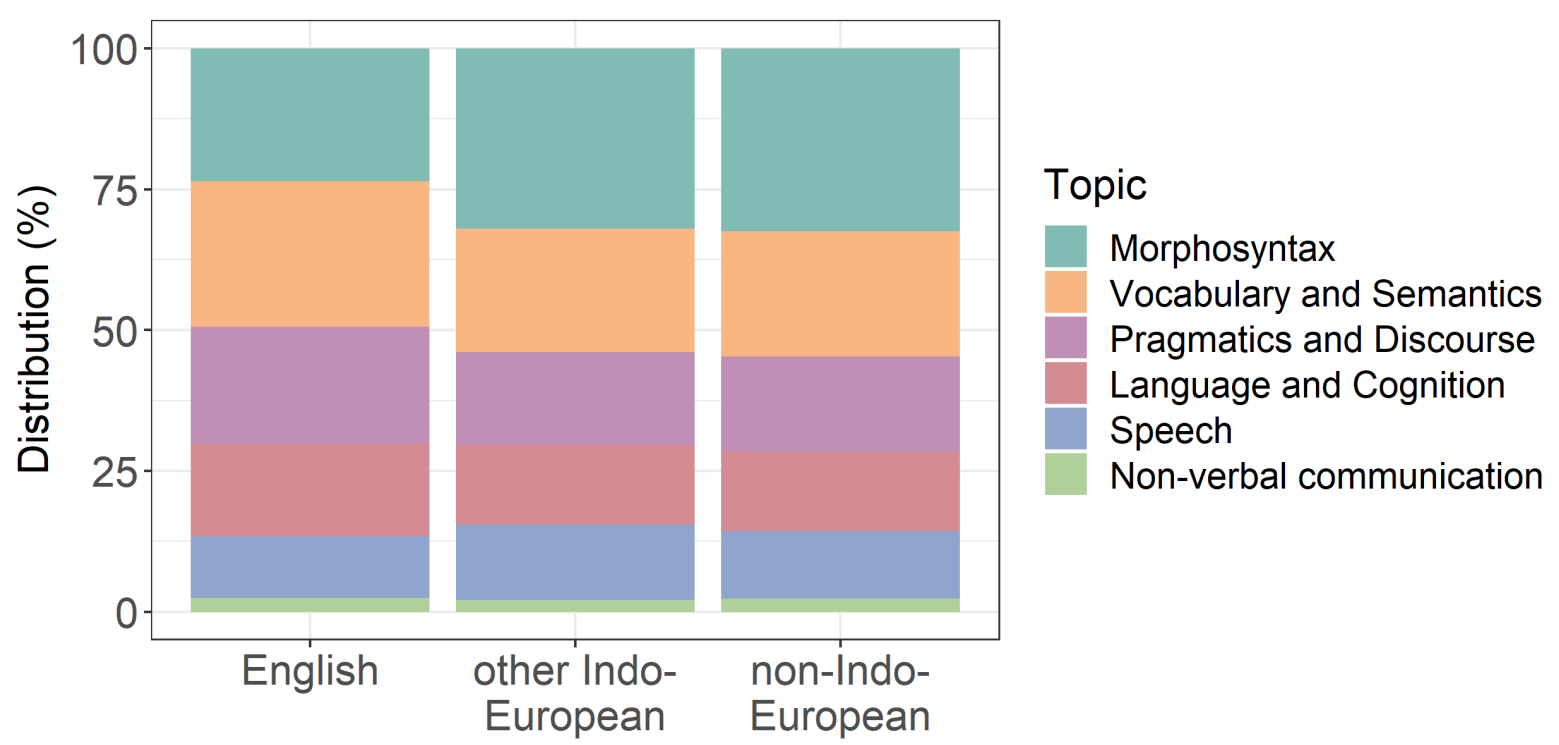

Figure 6. Distribution of topics of articles published in child language journals between 1974 and 2020 in different language groups.

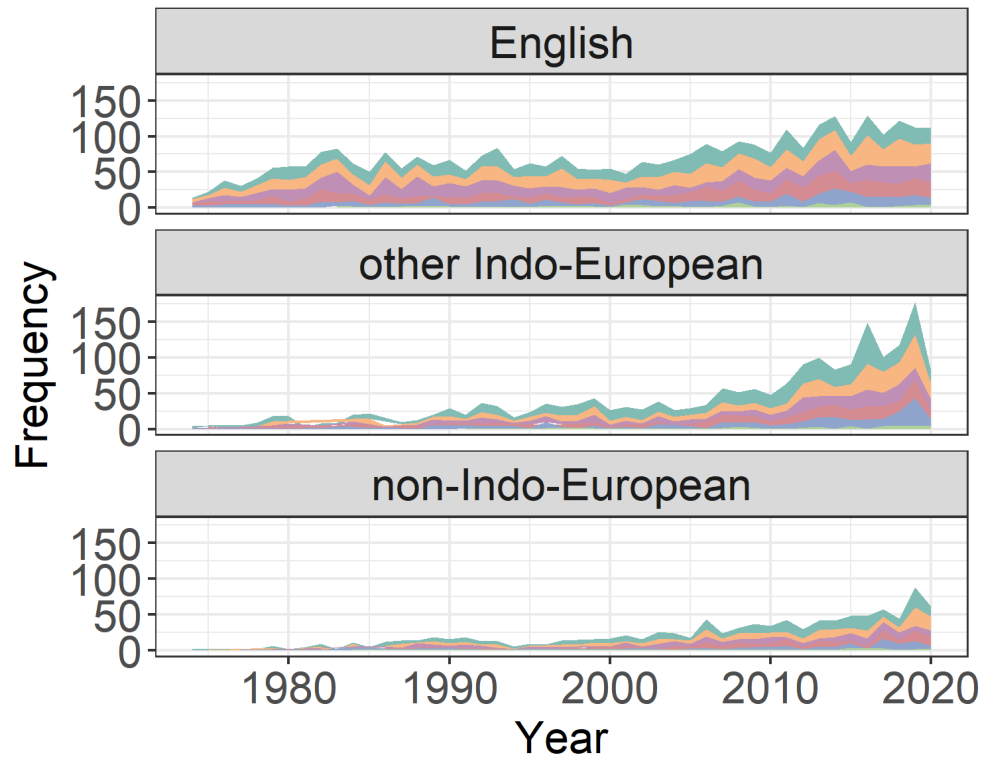

Topic

Morphosyntax Vocabulary and Semantics Pragmatics and Discourse Language and Cognition Speech Non-verbal communication

Figure 7. Distribution of topics of articles published in child language journals per year between 1974 and 2020 in different language groups.

We again fitted Poisson regression models to investigate whether there are differences in the growth rate of articles in a particular topic among language groups using the same 
strategy as for the overall data set. The data and model predictions for each individual topic are shown in Figure 8, with the model output in Table 4. The results show that the general trend across the three language groups (as reported in the Languages subsection) is replicated in all of the topics except for Speech and Non-verbal communication, which had the least amount of data. There is a linear growth for English, and exponential growth of published articles for other Indo-European and non-Indo-European languages. For Speech, there seems to be linear growth for both English and non-Indo-European languages, but exponential growth for other Indo-European languages. For Non-verbal communication the predicted growth is linear for all language groups.

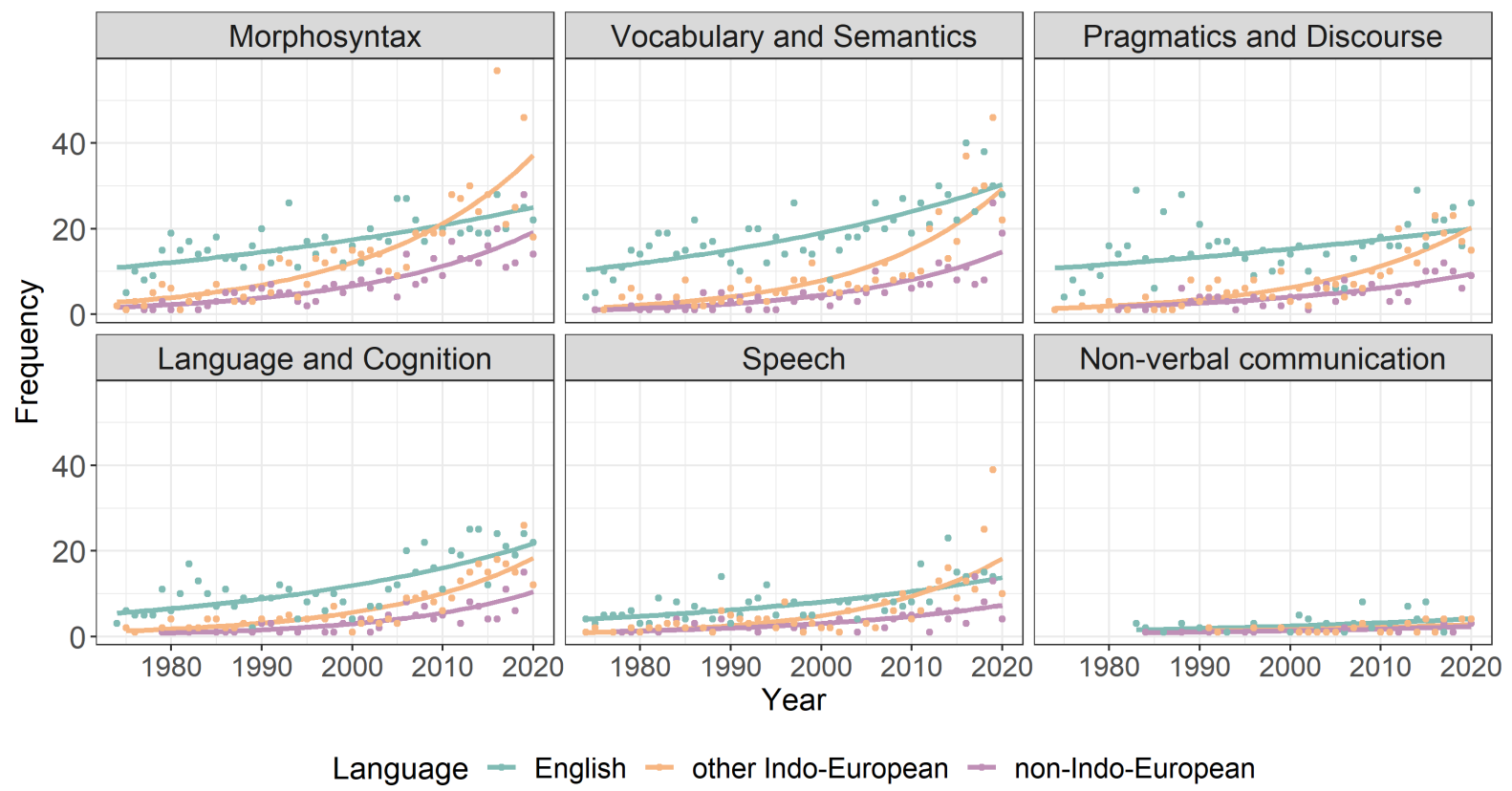

Figure 8. The number of articles published on different topics and language groups per year. The dots correspond to the actual number of articles (i.e., the raw data), while the lines correspond to the values predicted by the regression models. 
Table 4.

Final Regression Models Predicting Number of Articles by Year and Language Group for Each Topic.

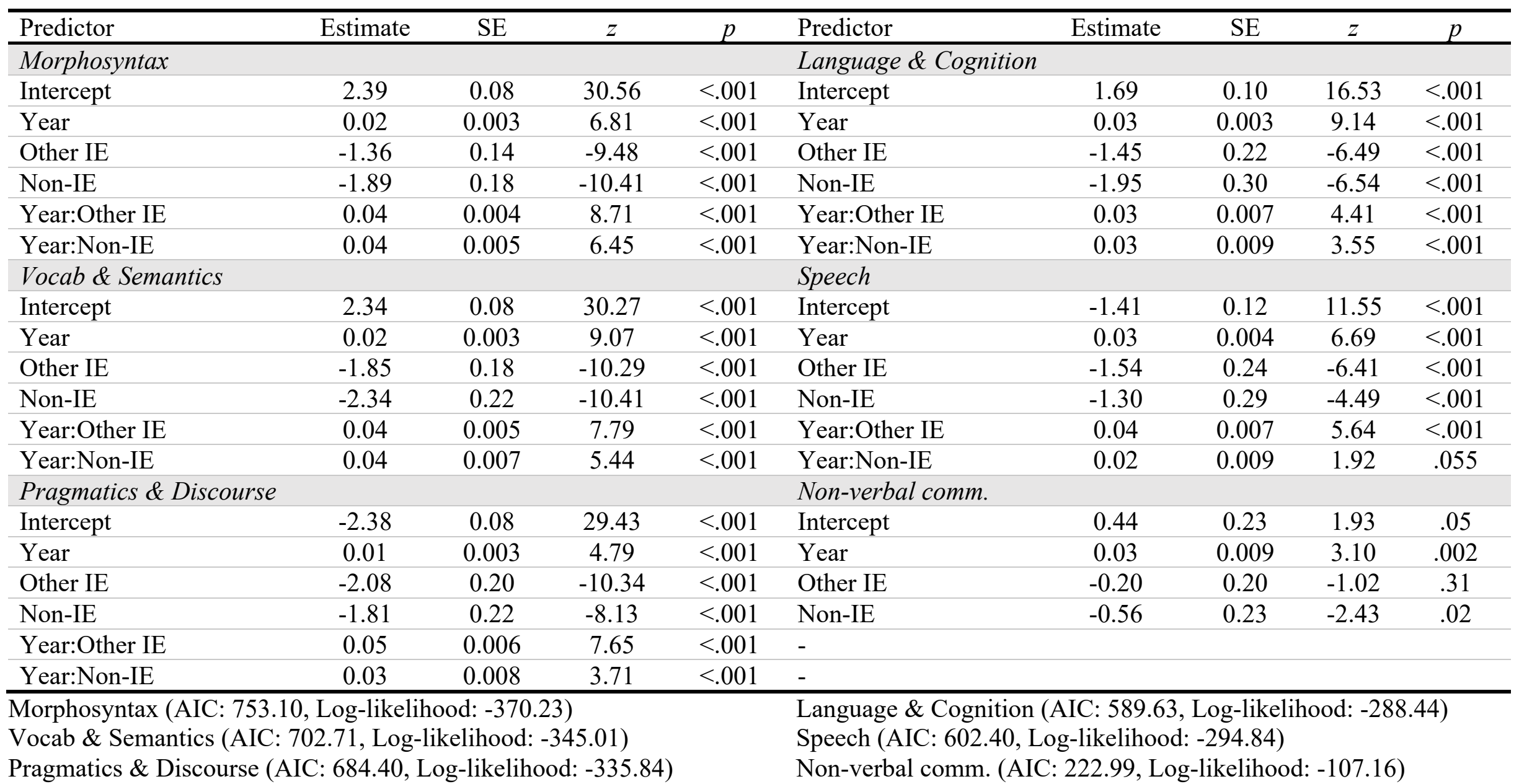




\section{Countries/Regions}

Figure 9 shows the distribution of region of author affiliations over time, divided into three categories: (i) North America, (ii) Europe, and (iii) Others. The creation of these categories was data-driven, recognising the heavy skew towards North America (49\%) and Europe (38\%). That is, $87 \%$ of papers had authors from these two regions. The remainder had authors in institutions in Australia and New Zealand (4\%), East Asia (4\%), West Asia (4\%), and only 1\% for Latin America, Sub-Saharan Africa, and South and Southeast Asia combined (for raw frequencies by country see Appendix B). Within-group analyses showed that most of the articles published by authors in Europe were from institutions in Northern and Western Europe (82\%), with only 3\% from institutions in Eastern Europe. These Northern and Western European countries in our list are traditionally the wealthiest in the region (Eurostat, 2021). Additionally, $80 \%$ of the articles from institutions in West Asia were from Israel, and $12 \%$ were from Turkey.

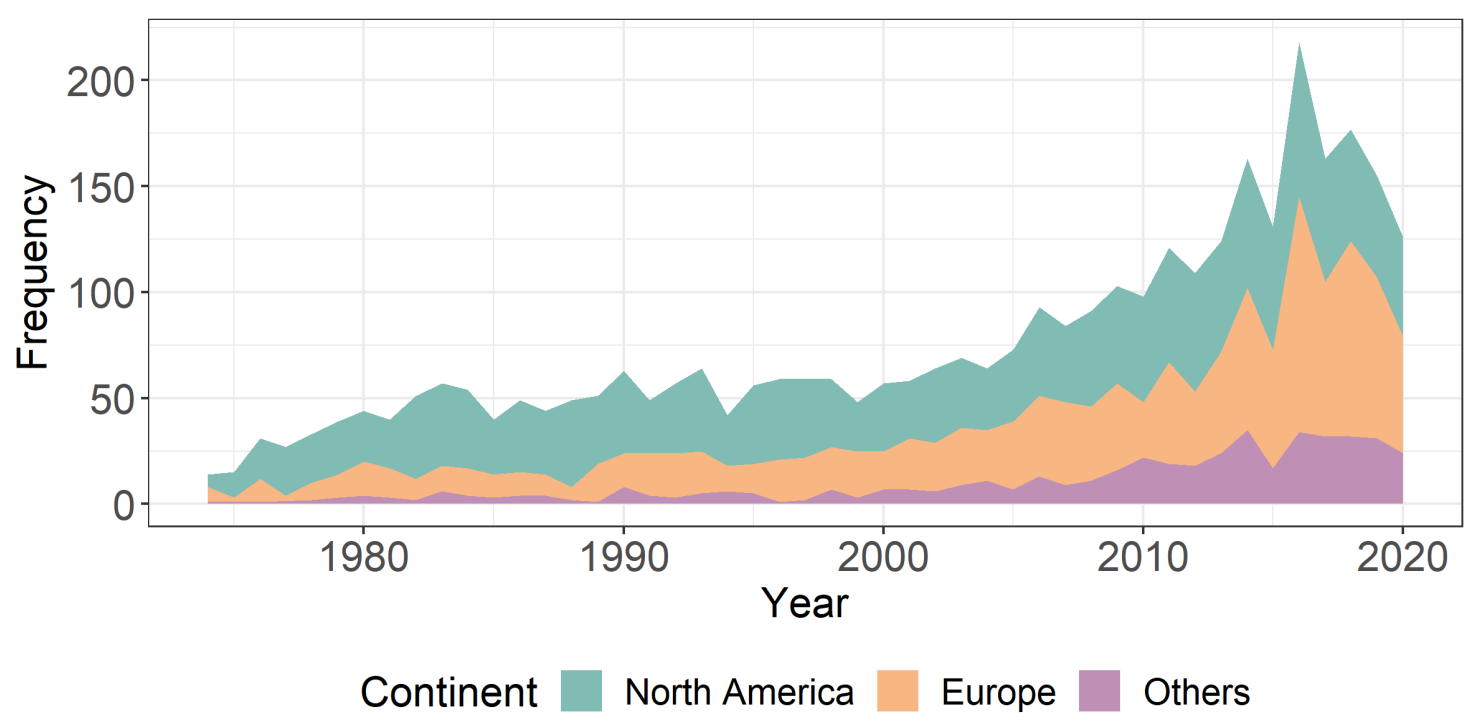

Figure 9. Distribution of regions of affiliations of the authors who published articles in child language journals per year between 1974 and 2020. 
We analysed these data using Poisson regression. Region of affiliation (referred to here as 'continent': North America, Europe, others) was treatment coded, with North America selected as the reference level so that the coefficients could be interpreted as to how publication rates in the other two categories differed from the most frequent contributing region. Year of publication was again adjusted with the first year (1974) being treated as 0 and was entered as a continuous independent variable. The model showed significant main effects and interaction of year and continent of author affiliation (see Table 5). Plotting the predictions of the model shows that the number of articles published by authors in North America is growing linearly, while the number of articles produced by authors in Europe and in other continents is growing exponentially, as shown in Figure 10.

\section{Table 5.}

Final Regression Models Predicting Number of Articles by Year and Region.

\begin{tabular}{lllll}
\hline \hline Predictor & Estimate & SE & $z$ value & $p$ value \\
\hline Intercept & 3.06 & 0.05 & 56.11 & $<.001$ \\
Year & 0.02 & 0.002 & 11.95 & $<.001$ \\
Europe & -1.29 & 0.10 & -13.16 & $<.001$ \\
Others & -2.87 & 0.17 & -16.84 & $<.001$ \\
Year:Europe & 0.03 & 0.003 & 11.62 & $<.001$ \\
Year:Others & 0.05 & 0.005 & 10.51 & $<.001$ \\
\hline
\end{tabular}

AIC: 904.62, Log-likelihood: -445.99

Figure 10 indicates that, collectively, the publication rate of authors outside North America is growing more rapidly than that of authors affiliated in North America. This is similar to the pattern of results in our analysis of languages, which reflects the fact that 
research on English, a large amount of which is produced in the United States of America, is growing at a slower rate than research on languages other than English.

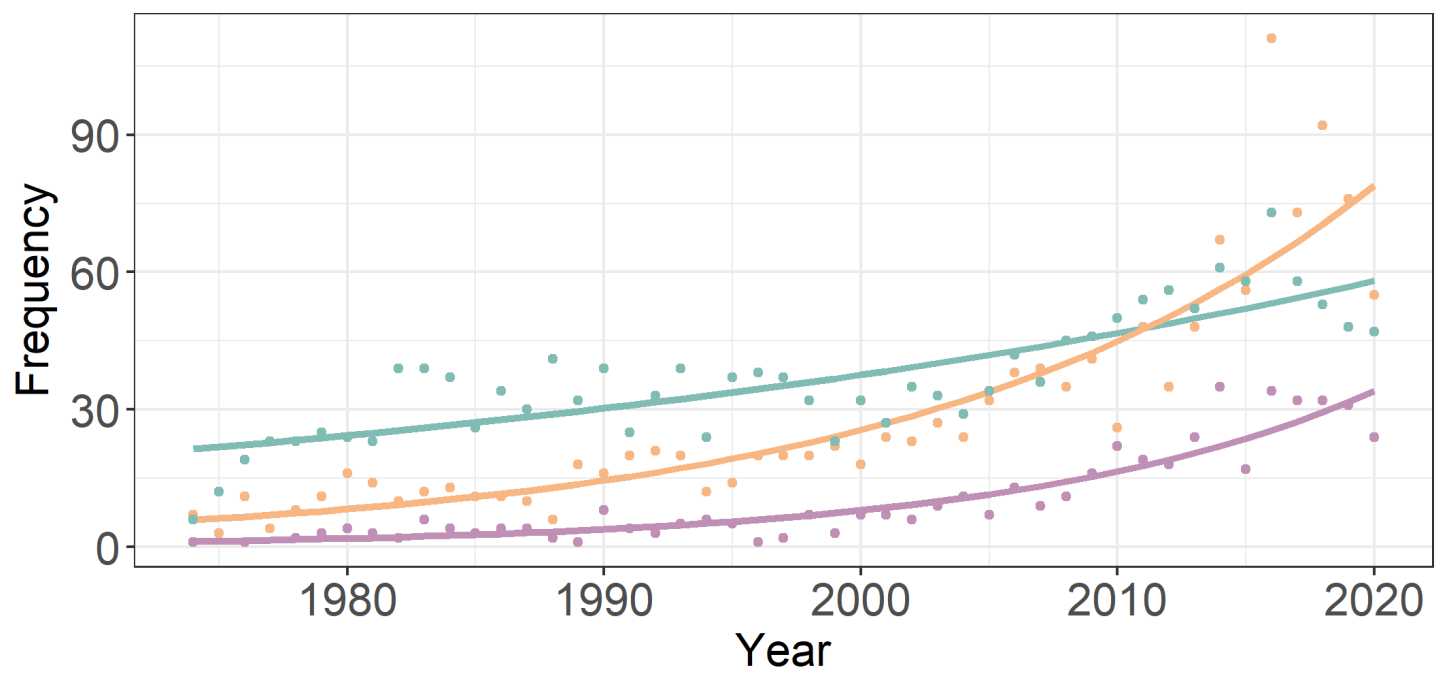

Continent - North America - Europe - Others

Figure 10. The number of articles published by authors with affiliations in different continents per year. The dots correspond to the actual number of articles (i.e., the raw data), while the lines correspond to the values predicted by the regression model.

\section{Discussion}

In this paper we aimed to determine the diversity of child language acquisition research over the modern history of the field by coding all articles published in the field's four main journals, since their inception until the end of 2020. We were primarily interested in language coverage, but also analysed the distribution of research topics and the locus of research production, as defined by the country of authors' affiliations. While we found a healthy distribution of topics covered, the field only has data for around $1.47 \%$ of the world's languages. This sample is heavily skewed towards English and other Indo-European languages, a result mirrored in the analysis of who produced the research, where $87 \%$ of the articles had authors based in North America or Europe. Our knowledge of languages outside of Indo-European (including English) is comparatively poor, with most languages having 
only one article published on them. While there are signs that the field is diversifying in terms of the number of authors based outside of North America, authors from the Global South are rare. In the remainder of the paper, we discuss the implications of the results, and review some suggestions for ways of increasing data coverage.

The estimate of language coverage is slightly higher than previously reported by Lieven and Stoll (2009), Crystal (2014), and Slobin (2014), although it is not a great deal higher. We acknowledge that the number could be higher because child language research is published outside of the four journals we coded. Our research is published across a wide range of linguistics and psychology journals, and in edited volumes and conferences proceedings. Articles on non-Indo-European languages also appear in domestic or specialised linguistics journals (e.g., Meakins \& Algy, 2016; Pye, 2013). Unfortunately, we (somewhat pessimistically) doubt that widening our search would have changed the estimate drastically: developmental psychology journals appear to have an even more extreme bias than we see in child language acquisition (see Nielsen et al., 2017), and coverage in major child language conferences is quite similar to the larger set of findings we report here (Kelly \& Nordlinger, 2014), suggesting that widening the search to other journals may would not improve the result. Finally, all but two languages (Georgian, Kaluli) that appeared in Slobin's (1985 1997) book series are contained in our dataset.

It appears, then, that much of what we know about child language acquisition comes from Indo-European languages, with a weighty proportion of the published research coming from studies of English. It is important to consider the degree to which this might be a problem. While Indo-European covers the largest area of the globe and has the largest number of speakers (an outcome of colonialism), it is only the sixth-largest family in terms of number of languages, containing 445 (Eberhard et al., 2021). Compare this to the two largest families, Niger-Congo and Austronesian, which are estimated to have 1,535 and 1,225 
languages, respectively. Or to Trans-New Guinea, whose 477 languages show remarkable diversity even though they are geographically packed into a comparatively tiny area (Pawley \& Hammaström, 2018). Languages diversify unevenly across the globe, with greater diversity within the Tropics (Gorenflo, Romaine, Mittermeier, \& Walker-Painemilla, 2012), far away from the Global North countries that produce most of our research. In many respects, we will not be able to lay claim to having representative and generalisable theories of child language acquisition until we can redress this balance. Or as Pye (2021) puts it: "the data needed to construct a representative sample of languages to test acquisition theories in a meaningful way do not exist" (p. 454).

It is instructive to consider the typological space our current data inhabits and what we might be missing out on. The majority of child language data comes from the languages of the European continent. While these languages show some diversity, they also have recognisable, common features, many of which are typologically rare in other language families. These include: definite and indefinite articles, relative clauses with relative pronouns, the 'have'-perfect, nominative experiencers, participial passives, negative pronouns and a lack of verbal negation, and verb fronting in polar interrogatives (for full list of 'Standard Average European' see Haspelmath, 2001, on the exceptionality of northwestern European languages, see Cysouw, 2011). This skew means that we know much less about features more common outside of European sprachbund, such as tone (Singh \& Fu, 2016), polysynthesis (Kelly, Nordlinger, Wigglesworth, \& Blythe, 2014; Mithun, 1989), obviation (Henke, 2021), ergativity (Bavin \& Stoll, 2013), and clause chaining (Sarvasy \& Choi, 2020), to name but a few. It also limits our understanding of how children might acquire typologically rarer phenomena (e.g., symmetrical 'Philippine-style' voice, see Garcia \& Kidd, 2020), which are existence proofs of what is possible in natural language and may be particularly challenging to theories built primarily on very different languages. We once 
again reiterate that these understudied features cannot be assumed to be surface variations masking the same underlying system; they represent unique design solutions to the core function of language - communication - having independently evolved across many successive generations of individual cultural groups. The degree to which such variation reflects any underlying core system of knowledge is an empirical question, but we will not answer it by concentrating on a handful of languages.

Some readers may rightly point out here that we have mostly listed a range of morphosyntactic features, but no component of language is crosslinguistically invariable (Evans \& Levinson, 2009). Accordingly, phonological systems vary as much as grammatical systems, and so too does the concept of 'word', which is less easily divorced from grammar in morphologically-rich languages than it is in analytic languages like English. Thus, a child acquiring the polysynthetic language Murrinhpatha (non-Pama-Nyungan, Australia), where a whole clause is expressed in a complex verb phrase, is faced with a very different problem when learning verbs compared to a child acquiring English or German (Forshaw, 2021). Taking a crosslinguistic approach seems even more important as we move away from the 'nuts and bolts' of language to topics that heavily interface with culture, such as pragmatics and discourse (e.g., event packaging in narrative, Berman \& Slobin, 1994; politeness, Chang, Tatsumi, Hayakawa, Yoshizaki, \& Oka, 2021), non-verbal communication (e.g., gesture, Özyürek, Kita, Allen, Furman, Brown, \& Ishizuka, 2008), and language and cognition (e.g., neo-Whorfian work, Majid, Bowerman, Kita, Haun, \& Levinson, 2004).

It is important to emphasise that, while there is much more work to do in order to address sampling bias in child language acquisition research, there is no reason to think that some established patterns in acquisition would not replicate beyond self-evident aspects of learning (e.g., children's production become more grammatically complex with age). Our current evidence base contains many patterns that are suggestive of dynamic underlying 
organisation. For instance, early in acquisition young children produce prosodicallyconstrained truncated words, the manner in which they do so varying by language (Demuth, 1996; Forshaw, 2021; Fikkert, 1994). Crosslinguistically, there is an observable though not invariable preference to relativise syntactic subjects (see Kidd, 2011; Lau \& Tanaka, 2021). When and in what languages these patterns emerge provides important clues regarding the complex interplay between the mechanisms children bring to language acquisition and how those mechanisms act on the input throughout development. Crosslinguistic research is essential to this effort (Bowerman, 2011; Slobin \& Bowerman, 2007).

Accordingly, the evidence base is in dire need of widening. We are currently working from such a skewed sample that we need data from big languages, smaller but healthy ones, and most urgently, endangered ones (where those languages have children acquiring them). With respect to big (or at least, 'largish') languages, there are real opportunities for researchers interested in languages like Georgian, Kazakh, Indonesian, Telugu, or Thai, to name but a few. However, unlike these languages, the majority of the world's languages do not have millions of speakers. Citing Ethnologue, Pye (2021) notes that $80.5 \%$ of the world's languages have under 100,000 speakers. Though speaker numbers are an imperfect guide to endangerment (i.e., many small languages thrive under the right conditions), the link between speaker numbers and language health is a legitimate one. Pye writes:

Testing a theory of language acquisition with data from 19.5\% of human languages cannot be justified. A sample that is typologically skewed toward Indo-European languages makes a bad situation worse (Pye, 2021, p. 455).

Currently our theories are based on less than $2 \%$ of the world's languages, so we some way from $19.5 \%$. A reasonable question, then, is how can we begin to redress the imbalance? There are beginnings of movement in this space, but a step change in capacity 
needed. Pye (2021) argues that one practical and productive way to widen the evidential base is to focus on lexical acquisition in endangered languages. Along similar lines, Defina, et al. (2021) have developed a set of guidelines for an 'acquisition sketch', in which a researcher would write an overview of acquisition for understudied languages, endangered or otherwise, using a minimum of 5 hours of naturalistic data. Both of these approaches aim at rapidly widening the breadth of languages for which we have data, attempting to integrate insights from language documentation into child language acquisition. This breadth approach complements approaches that aim for greater depth, such as the ACQDIV project (Jansco, Moran, \& Stoll, 2020), which samples typologically distant languages with good child language corpora to attempt to draw broadly generalisable conclusions about acquisition.

However, many aspects of working on understudied languages is time-intensive (and in the case of endangered languages, particularly difficult, Kelly, Forshaw, Nordlinger, \& Wigglesworth, 2015), such that we will never achieve representative sample unless we make drastic changes to the way we collect data and who collects it. Technology has a big role to play. In particular, there have been exciting developments in daylong recording technology (Casillas \& Cristia, 2019), and we can hope for a day when much of the transcription bottleneck is alleviated by good speech-to-text transcription. The COVID-19 pandemic has also ramped up the development of data collection via the internet, such that it is possible to collect corpus data and run experiments via the internet if participants have reasonable internet connections (Garcia, Roeser, \& Kidd, 2021; Mai, Zhao, \& Yip, 2017).

Even if we vastly improve automated transcription, we still need trained researchers to interpret and analyse the data. This process is made substantially easier if the researcher already has a good command of the target language. Here is where our results for the locus of research production are particularly pertinent. Child language acquisition, it seems, is dominated by researchers from wealthy, industrialised countries. As gatekeepers to the 
kingdom, only we can change this. Recent movement in this space has included the Truly

Global /L+/Summer/Winter School on Language Acquisition ${ }^{7}$, aimed specifically at students from the Global South. However, a much bigger effort framed around discussions concerning diversity in the workplace is required at the institutional level. It is incumbent on us as the custodians of the discipline to move the goals of the field into a direction that will more easily allow and reward research on child language acquisition in understudied languages across every component of the discipline, from student theses to professional recognition at the university and field level (e.g., for grant applications, in our journals, lobbying institutions for greater recognition of non-standard outputs such as corpora, see Thieberger, Margetts, Morey, \& Musgrave, 2016). For many students who speak an understudied language, this may require alternative pathways to study and additional support in skills training. Insofar as this will diversify our discipline, it is hard work worth doing. ${ }^{8}$

One encouraging feature of the results is that, while there is some variability in the topics to which child language research has been devoted, we observed almost the same distribution within our language categories, and the growth rates for each individual topic excluding Non-verbal communication are all qualitatively similar. That is, we found linear growth across all topics in studies of English, and non-linear growth in other Indo-European languages and non-Indo-European languages (although for Speech the contrast between English and non-Indo-European was positive but not significant). The difference in result was most likely due to low numbers of articles investigating Non-verbal communication, where growth across all language groups was linear, which likely reflects the relatively young age of this subdiscipline and the fact that there are specialist journals devoted to the topic (e.g.,

\footnotetext{
${ }^{7}$ https://www.dpss.unipd.it/summer-school-2021/home

${ }^{8}$ Space limitations prevent us from addressing this issue in more detail, but we are aware that it is not nearly as simple as 'build it and they will come'. The reality is that we work in a very specialised field that has relatively low visibility to bright young minds, especially those from backgrounds that are not well represented in our institutions. We hope that our paper inspires readers to develop innovative solutions to the problem.
} 
Journal of Non-Verbal Behavior, Gesture). Thus, when researchers have studied languages other than English, their questions are not skewed in ways that are not representative of the field as a whole. Overall, research on languages other than English is contributing at a more rapid rate to progress in the field than is work on English.

As a final point, we stress that we are not claiming that further work on well-studied languages is not needed. On the contrary, the large volume of past work on these languages allows researchers to ask different kinds of questions precisely because acquisition is so well mapped out. For example, the development of accurate measurement tools such as standardised tests of language proficiency and tests of cognitive function (e.g., memory, attention) allows researchers to ask questions about the sources and consequences of individual differences in acquisition (Bates, Dale, \& Thal, 1995; Kidd \& Donnelly, 2020), including the underlying sources of language delay. Additionally, a lot of work on wellstudied languages involves experimentation, which is not always as easy to conduct in understudied languages, where naturalistic data collection might be an important first step. Experimentation is the foundation of any science, and there are many important questions that we can ask of well-studied languages, provided that we are aware that the conclusions that we make and mechanisms we propose are reasonable and flexible enough to hold crosslinguistically.

\section{Conclusions}

In the current paper we have taken stock of the past child language literature published in the field's four main journals to determine the degree of language coverage to which the field can lay, whether this has changed over time, the kinds of topics on which research is published, and from which regions researchers come. The overall finding echoes similar analyses in related disciplines such as developmental psychology (Nielsen et al., 2017) and adult psycholinguistics (Anand et al., 2011; Jaeger \& Norcliffe, 2009): child 
language acquisition is not very diverse. Our research base draws from less than $2 \%$ of the world's languages, with most of our evidential base skewed towards English and other wellstudied Indo-European languages. We found evidence that the field is moving away from a historical reliance on English (Slobin, 2104); however, it is important to remember that much of the diversity we found is concentrated in the Global North or in other comparatively wealthy countries with emerging research cultures. A concerted effort is needed to further diversify the field so that we can both build scientifically generalisable theories and a more diverse research community. 


\section{References}

Allen, S. E. \& Crago, M. B. (1996). Early passive acquisition in Inuktitut. Journal of Child Language, 23, 129 - 156. doi:10.1017/s0305000900010126.

Anand, E., Chung, S., \& Wagers, M. (2011). Widening the net: Challenges for gathering linguistic data in the digital age. NSF SBE 2020. Rebuilding the mosaic: Future research in the social, behavioral and economic sciences at the National Science Foundation in the next decade.

Bates E., Dale P., \& Thal D. (1995). Individual differences and their implications for theories of language development. In P. Fletcher \& B. MacWhinney, (Eds.), Handbook of Child Language, (pp. 96 - 151). Oxford, UK: Basil Blackwell.

Bates, D., Maechler, M., Bolker, B. and Walker, S. (2015). Fitting Linear Mixed-Effects Models Using lme4. Journal of Statistical Software, 67, 1 - 48. doi: 10.18637/jss.v067.i01

Bavin, E. L. (1992). The acquisition of Warlpiri. In D. I. Slobin (Ed.), The crosslinguistic acquisition of language acquisition, Vol. 3. (pp. 309 - 371). Hillsdale, NJ: Lawrence Erlbaum.

Bavin, E. L. (1995). Language acquisition in crosslinguistic context. Annual Review of Anthropology, 24, 373 - 396. https://www.jstor.org/stable/2155942

Bavin, E., L., \& Stoll, S. (Eds.) (2013). The acquisition of ergativity. Amsterdam: John Benjamins,

Berman, R. A. (2014). Crosslinguistic comparisons in child language research. Journal of Child Language, 40 (S1), 26 - 37. doi.org/10.1017/S0305000914000208

Berman, R. A. \& Slobin, D. I. (Eds.) (1994). Relating events in narrative: A crosslinguistic developmental study. Hillsdale, NJ: Lawrence Erlbaum. 
Bernstein-Ratner, N. \& Pye, C. (1984). Higher pitch in BT is not universal: acoustic evidence from Quiché Mayan. Journal of Child Language, 11, 515 - 522. doi.org/10.1017/S0305000900005924

Borer, H., \& Wexler, K. (1987). The maturation of syntax. In T. Roeper \& E. Williams (Eds.), Parameter setting, (pp. 123-172). Dordrecht, Holland: Reidel.

Bowerman, M. (2011). Linguistic typology and first language acquisition. In J. J. Song (Ed.), The Oxford handbook of linguistic typology, (pp. 591 - 617). Oxford: Oxford University Press.

Brown, P. (2012). The cultural organization of attention. In A. Duranti, E. Ochs, \& B. B. Schieffelin (Eds.), The handbook of language socialization, (pp. 29 - 55). Malden: Wiley-Blackwell.

Campbell, L., Heaton, R., Lee, N. H., Okura, E., Simpson, S., Ueki, K., \& Van Way, J. (2013). New Knowledge: Findings from the Catalogue of Endangered Languages ("ELCat"). 3rd International Conference on Language Documentation \& Conservation.

Casillas, M., Brown, P., \& Levinson, S. C. (2020). Early language experience in a Tseltal Mayan village. Child Development, 91, 1819-1835. doi:10.1111/cdev.13349.

Casillas, M., \& Cristia, A. (2019). A step-by-step guide to collecting and analyzing longformat speech environment (LFSE) recordings. Collabra, 5: 24. doi:10.1525/collabra.209

Chan, A., Yang, W., Chang, F., \& Kidd, E. (2018). Four-year-old Cantonese-speaking children's online processing of relative clauses: A permutation analysis. Journal of Child Language, 45, 174-203. doi:10.1017/s0305000917000198. 
Chang, F., Tatsumi, T., Hayakawa, H., Yoshizaki, M., Oka, N. (2021) The role of parental input in the acquisition of Japanese politeness distinctions Collabra: Psychology, 7, 18989. https://doi.org/10.1525/collabra. 18989

Crystal, D. (2014). Editorial. Journal of Child Language, 41 (S1), v - vi.

Cysouw, M. (2011). Quantitative explorations of the worldwide distribution of rare characteristics, or: the exceptionality of northwestern European languages. In S. J. Horst \& H. Wiese (eds.). Expecting the unexpected: Exceptions in grammar, (pp. 411 - 432). Berlin: Mouton de Gruyter. 411-432.

Dabrowska, E. \& Szczerbinski, M. (2006). Polish children's productivity with case marking: the role of regularity, type frequency, and phonological diversity. Journal of Child Language, 33,559 - 597. doi.org/10.1017/S0305000906007471

Defina, R., Allen, S., Davidson, L., Hellwig, B., Kelly, B., \& Kidd, E. (2021). The sketch acquisition manual. Unpublished manuscruipt.

de León, L. (2012). Language socialization and multi-party participation frameworks. In A. Duranti, E. Ochs, \& B. B. Schieffelin (Eds.), The handbook of language socialization, (pp. 81 - 111). Malden: Wiley-Blackwell.

Demuth, K. (1989). Maturation and the acquisition of Sesotho passive. Language, 65, 56 80. https://doi.org/10.2307/414842

Demuth, K. (1996). The prosodic structure of early words. In J. Morgan \& K. Demuth (Eds.), Signal to Syntax: Bootstrapping from speech to grammar in early acquisition (pp. 171 - 184). Lawrence Erlbaum Associates.

Eberhard, D.M., Simons, G.F., \& Fenning, C.D. (2021). Ethnologue: Languages of the world, 24th edition. Dallas: SIL International. Online: https://www.ethnologue.com

Engelmann, F., Granlund, S., Kolak, J., Zreder, M., Ambridge, B., Pine, J. M., Theakston, A. L., \& Lieven, E. V. M. (2019). How the input shapes the acquisition of verb 
morphology: Elicited production and computational modelling in two highly inflected languages. Cognitive Psychology, 110, $30-69$.

https://doi.org/10.1016/j.cogpsych.2019.02.001

Evans, N. (2010). Dying words: Endangered languages and what they have to tell us. Oxford: Wiley-Blackwell.

Evans, N., \& Levinson, S. C. (2009). The myth of language universals: Language diversity and its importance to cognitive science. Behavioral and Brain Sciences, 32, 429 - 92. doi: $10.1017 / \mathrm{S} 0140525 \mathrm{X} 0999094 \mathrm{X}$

Eurostat (2021). GDP per capita, consumption per capita and price level indices [Data file]. Retrieved from https://ec.europa.eu/eurostat/statisticsexplained/index.php?title=GDP_per_capita,_con sumption_per_capita_and_price_level_indices\#Relative_volumes_of_GDP_per_capit $\underline{\mathrm{a}}$

Fikkert, P. (1994). On the acquisition of prosodic structure. Nijmegen: Radboud University. Retrieved from: https://repository.ubn.ru.nl/bitstream/handle/2066/32125/on thaco.pdf

Forshaw, W. (2021). The acquisition of complex morphology: Insights from Murrinhpatha. Amsterdam: John Benjamins.

Gallois, C., Ogay, T., \& Giles, H. (2005). Communication accommodation theory: A look back and a look ahead. In W. B. Gudykunst (Ed.), Theorizing about communication and culture (pp. 121 - 148). Thousand Oaks, CA: Sage.

Garcia, R., Garrido Rodriguez, G., \& Kidd, E. (2021). Developmental effects in the online use of morphosyntactic cues in sentence processing: Evidence from Tagalog. Cognition, 216: 104859. doi:10.1016/j.cognition.2021.104859. 
Garcia, R., \& Kidd, E. (2020). The acquisition of the Tagalog symmetrical voice system: Evidence from structural priming. Language Learning and Development, 16, 399425. doi:10.1080/15475441.2020.1814780.

Garcia, R., Roeser, J., \& Kidd, E. (2021). On-line data collection to address sampling bias: Lessons from the COVID-19 pandemic. Unpublished manuscript.

Gil, D. (2006). The acquisition of voice morphology in Jakarta Indonesian. In N. Gagarina \& I. Gülzow (Eds.), The acquisition of verbs and their grammar: The effect of particular languages (pp. 201 - 227). Dordrecht: Springer.

Giles, H., Coupland, N., \& Coupland, J. (1991). Accommodation theory: Communication, context, and consequence. In H. Giles, J. Coupland, \& N. Coupland (Eds.), Contexts of accommodation (pp. 1-68). Cambridge, UK: Cambridge University Press.

Gorenflo, L. J., Romaine, S., Mittermeier, R. A., \& Walker-Painemilla, K. (2012). Cooccurrence of linguistic and biological diversity in biodiversity hotspots and high biodiversity wilderness areas. Proceedings of the National Academy of Sciences, 109, 8032 - 8037. doi: 10.1073/pnas. 1117511109.

Granlund, S., Kolak, J., Vihman, V. Engelmann, F., Lieven, E. V. M., Pine, J. M., Theakston, A., \& Ambridge, B. (2019). Language-general and language-specific phenomena in the acquisition of inflectional morphology. A crosslinguistic elicited production study of Polish, Finnish, and Estonian. Journal of Memory and Language, 107, 169 - 194. https://doi.org/10.1016/j.jml.2019.04.004

Hale, K. (1992). Language endangerment and the human value of linguistic diversity. Language, 68, 35 - 42. Doi: 10.1353/lan,.1992.0052.

Hallett, D., Chandler, M. J., \& Lalonde, C. E. (2007). Aboriginal language knowledge and youth suicide. Cognitive Development, 22, 392 - 399. doi:10.1016/j.cogdev.2007.02.001 
Haspelmath, M. (2001). The European linguistic area: Standard Average European. In M. Haspelmath, E. König, W. Oesterreicher, \& W. Raible (Eds.), Language typology and language universals: An international handbook (pp. 1492 - 1510). Berlin: Mouton de Gruyter.

Hellwig, B., Defina, B., Kidd, E., Allen, S., Davidson, L., \& Kelly, B. F. (2021). Child language documentation: The Sketch Acquisition Project. In Geoffrey Haig, Stefan Schnell \& Frank Seifart (eds.). Advances in corpus-based typology: State of the art. Language Documentation and Conservation.

Henke, R. E. (2021). The acquisition of obviation in Northern East Cree: Evidence from possessive constructions. In M. Macaulay \& M. Noodin (Eds.), Papers of the Fiftieth Algonquian Conference, (pp. 113 - 134). East Lansing: Michigan State University Press.

Heinrich, J., Heins, S. J., \& Norenzayan, A. (2010). The weirdest people in the world? Behavioral \& Brain Sciences, 33, $61-83$. https://doi.org/10.1017/S0140525X0999152X

Himmelmann, N. P. (1998). Documentary and descriptive linguistics. Linguistics, 36, 161 195. doi: 10.1515/ling.1998.36.1.161.

Holes, C. (2004). Modern Arabic: structures, functions, and varieties. Washington, DC: Georgetown University Press, 2004.

Holtgraves, T. M., \& Kashima, Y. (2008). Language, meaning, and social cognition. Personality and Social Psychology Review, 12, 73 - 94. doi:10.1177/1088868307309605

Ingram, D. (1995). The cultural basis of prosodic modifications to infants and children: a response to Fernald's universalist theory. Journal of Child Language, 22, 223 - 233. doi: $10.10117 / \mathrm{S} 0305000900009715$. 
Jaeger, T. F. \& Norcliffe, E. J. (2009). The Cross-linguistic Study of Sentence

Production. Language and Linguistics Compass 3(4). 866-887.

https://doi.org/10.1111/j.1749-818X.2009.00147.x

Jansco, A., Moran, S., \& Stoll, S. (2020). The ACQDIV corpus and aggregation pipeline. In Proceedings of the 12th conference on language resources and evaluation, (pp. 156 165). European Language Resources Association.

Kelly, B. F., Forshaw, W., Nordlinger, R., \& Wigglesworth, G. (2015) Linguistic diversity in first language acquisition research: Moving beyond the challenges. First Language, 35, 286 - 304. doi: 10.1177/0142723715602350.

Kelly, B. F., \& Nordlinger, R. (2014). Fieldwork and first language acquisition. In L. Gawne \& J. Vaughn (Eds.), Selected papers from the $44^{\text {th }}$ conference of the Australian Linguistics Society, 2013. 178 - 192.

Kelly, B. F., Wigglesworth, G., Nordlinger, R., \& Blythe, J. (2014). The acquisition of polysynthetic languages. Language and Linguistics Compass, 8, 51 - 64. doi: $10.1111 / \operatorname{lnc} 3.12062$.

Kidd, E. (Ed.) (2011). The acquisition of relative clauses: Processing, typology, and function. Amsterdam: John Benjamins.

Kidd, E., \& Donnelly, S. (2020). Individual differences in first language acquisition. Annual Review of Linguistics, 6, 319-340. doi:10.1146/annurev-linguistics-011619-030326.

Lau, E., \& Tanaka, N. (2021). The subject advantage in relative clauses: A review. Glossa, 6. p.34. doi: https://doi.org/10.5334/gjgl.1343

Lieven, E. V. M. (1994). Crosslinguistic and crosscultural aspects of language addressed to children. In C. Gallaway \& B. J. Richards (Eds.), Input and interaction in language acquisition, (pp. 56 - 73). Cambridge, UK: Cambridge University Press. 
Lieven, E. V. M., \& Stoll, S. (2009). Language. In M. H. Bornstein (Ed.), The handbook of cultural developmental science, (pp. 143 - 160). New York: Psychology Press.

MacWhinney, B. (2000). The CHILDES project: Tools for analyzing talk (3 $\left.3^{\text {rd }} \mathrm{ed}.\right)$. Mahwah, NJ: Lawrence Erlbaum.

MacWhinney, B., \& Bates, E. (Eds.) (1989). The crosslinguistic study of sentence processing. New York: Cambridge University Press.

Mai, Z., Zhao, L., \& Yip, V. (2021). The Mandarin ba-construction in school-age heritage speakers and their parents. Linguistic Approaches to Bilingualism. doi: 10.1075/lab.18025.mai

Majid, A., Bowerman, M., Kita, S., Haun, D. B. M., \& Levinson, S. C. (2004). Can language restructure cognition? The case for space. Trends in Cognitive Sciences, 8,108 114. doi:10.1016/j.tics.2004.01.003

Marcus, G. F., Pinker, S. Ullman, M. T. Hollander, M., Rosen, T. J. \& Xu, F. (1992). Overregularization in language acquisition. Monographs of the Society for Research in Child Development 57 (4, Serial No. 228): 1-165. https://doi.org/10.2307/1166115

Mazerolle, M. J. (2020). AICcmodavg: Model selection and multimodel inference based on (Q)AIC(c). R package version 2.3-1, https://cran.r-project.org/package=AICcmodavg.

Meakins, F. \& Algy, C. (2016). Deadly reckoning: changes in Gurindji children's knowledge of cardinals. Australian Journal of Linguistics, 36, 479 - 501. doi: $10.1080 / 07268602.2016 .1169973$

Mithun, M. (1989). The acquisition of polysynthesis. Journal of Child Language, 16, 285 312. doi: $10.1017 / \mathrm{S} 0305000900010424$

Nielsen, M., Haun, D., Kärtner, J., \& Legare, C. H. (2017). The persistent sampling bias in developmental psychology: A call to action. Journal of Experimental Child Psychology, 162, 31-38. https://doi.org/10.1016/j.jecp.2017.04.017 
Ochs, E., \& Schieffelin, B. (1984). Language acquisition and socialization: Three developmental stories. In R. Shweder \& R. LeVine (Eds.), Culture theory: Mind, self, and emotion, (pp. 227 - 320). Cambridge: Cambridge University Press.

Ochs, E., \& Schieffelin, B. (2012). The theory of language socialization. In A. Duranti, E. Ochs, \& B. B. Schieffelin (Eds.), The handbook of language socialization, (pp. 1-21). Malden: Wiley-Blackwell.

Özyürek, A., Kita, S., Allen, S.E.M., Furman, R., Brown, A. \& Ishizuka, T. (2008). Development of cross- linguistic variation in speech and gesture: Motion events in English and Turkish. Developmental Psychology 44, 1040-1054. https://doi.org/10.1037/0012-1649.44.4.1040

Pawley, A., \& Hammarström, H. (2018). The Trans New Guinea family. In B. Palmer (ed.). The Languages and Linguistics of the New Guinea Area: A Comprehensive Guide, (pp. 21 - 196). The World of Linguistics. 4. Berlin: De Gruyter Mouton. Pinker, S. (1984). Language learnability and language development. Cambridge, MA: Harvard University Press.

Pinker, S. (1989). Learnability and cognition. Cambridge, MA: MIT Press.

Pinker, S. (1994). Words and rules: The ingredients of language. London: Phoenix.

Power, J. M., Grimm, G. W., \& List, J-M. (2020). Evolutionary dispersal of signed languages. Royal Society Open Science, 7(1), https://doi.org/10.1098/rsos.191100

Pye, C. (1986). Quiché Mayan speech to children. Journal of Child Language, 13, 85 - 100. https://doi.org/10.1017/S0305000900000313

Pye, C. (1990). The acquisition of ergative languages. Linguistics, 28, $1291-1330$. https://doi.org/10.1515/ling.1990.28.6.1291 
Pye, C. (2013). A tale of two Mam children: Contact induced language change in Mayan child language. International Journal of American Linguistics, 79, 555 - 575. https://www.jstor.org/stable/10.1086/671771

Pye, C. (2021). Documenting the acquisition of indigenous languages. Journal of Child Languages, 48, 454 - 479. doi: 10.1017/S0305000920000318.

R Core Team. (2020). R: A language and environment for statistical computing. $\mathrm{R}$ Foundation for Statistical Computing. https://www.R-project.org/.

Sarvasy, H. \& Choi, S. (2020), 'Beyond the two-clause sentence: acquisition of clause chaining in six languages', Frontiers in Psychology, 11, article 1586. doi: 10.3389/fpsyg.2020.01586.

Seifart, F., Evans, N., Hammarström, H., \& Levinson, S. (2018). Language documentation twenty-five years on. Language, 94, e324-e345.

Singh, L. \& Fu, C. S. L. (2016) A New View of Language Development: The acquisition of lexical tone. Child Development, 87, 834-854. doi: 10.111/cdev.12512

Slobin, D. I. (1973). Cognitive prerequisites for the development of grammar. In C.A. Ferguson \& D. I. Slobin (Eds.), Studies of child language development, (pp. 175 208). New York: Holt, Rinehart, \& Winston,

Slobin, D. I. (1985 - 1997). The crosslinguistic study of language acquisition, Vols 1 - 5. Hillsdale and Mahwah, NJ: Lawrence Erlbaum.

Slobin, D. I. \& Bowerman, M. (2007). Interfaces between linguistic typology and child language research. Linguistic Typology, 11, 213 - 226. doi: 10.1515/LINGTY.2007.015.

Stoll, S., Mazara, J., \& Bickel, B. (2017). The acquisition of polysynthetic verb forms in Chintang. In M. D. Fortescue, Mithun, M., \& Evans, N. The Oxford Handbook of Polysynthesis, (pp. 495 - 514). Oxford: Oxford University Press. 
Suzman, S. M. (1987). Passives and prototypes in Zulu children's speech. African Studies $46(2), 241-254$.

Thieberger, N., Margetts, A., Morey, S. \& Musgrave, S. (2016). Assessing Annotated Corpora as Research Output. Australian Journal of Linguistics, 36, 1 - 21. doi:10.1080/07268602.2016.1109428

United Nations Intergovernmental Science-Policy Platform On Biodiversity and Ecosystems Services (2019). Retrieved from https://ipbes.net/sites/default/files/downloads/general_message_primer_en.pdf. United Nations Statistics Division (2021). Standard country or area codes for statistical use (M49). Retrieved from https://unstats.un.org/unsd/methodology/m49/\#geo-regions Vygotsky, L. (1962). Thought and language. Cambridge, MA: The MIT Press. Yang, W., Yang, W., Chan, A., Chang, F., \& Kidd, E. (2020). Four-year-old Mandarin-speaking children's online comprehension of relative clauses. Cognition, 196, 104103. doi:10.1016/j.cognition.2019.104103. 


\section{Appendix A}

Table A1. Frequency distribution of articles on different languages published in child language journals from 1974 until 2020.

\begin{tabular}{|c|c|c|c|}
\hline Language & Freq. & Language & Freq. \\
\hline Afrikaans & 1 & Hindi & 3 \\
\hline American Sign Language & 16 & Hmong & 2 \\
\hline Arabic & 15 & Home sign & 2 \\
\hline Armenian & 1 & Huli & 1 \\
\hline Basque & 4 & Hungarian & 7 \\
\hline Bengali & 1 & Icelandic & 8 \\
\hline Bontok (Central) & 1 & Igbo & 1 \\
\hline British Sign Language & 6 & Indonesian & 1 \\
\hline Bulgarian & 3 & Inuktitut & 4 \\
\hline Cantonese & 28 & Irish & 8 \\
\hline Catalan & 18 & Italian & 114 \\
\hline Chintang & 1 & Jamaican Creole English & 2 \\
\hline Conchucos Quechua & 1 & Japanese & 63 \\
\hline Cree (Northern East) & 1 & K'iche' & 3 \\
\hline Czech & 5 & Kannada & 1 \\
\hline Danish & 14 & Kigiriama & 2 \\
\hline Dutch & 115 & Korean & 29 \\
\hline English & 1790 & Kurdish & 1 \\
\hline Esperanto & 1 & Latvian & 1 \\
\hline Estonian & 13 & Laz & 1 \\
\hline Faroese & 2 & Limburgian & 1 \\
\hline Farsi & 7 & LIS (Italian Sign Language) & 1 \\
\hline Finnish & 30 & Lisu & 1 \\
\hline French & 215 & Lithuanian & 5 \\
\hline Frisian & 3 & Malay & 3 \\
\hline Galician & 3 & Malayalam & 1 \\
\hline German & 136 & Maltese & 3 \\
\hline Greek & 26 & Mandarin & 83 \\
\hline Greenlandic & 1 & Maori & 2 \\
\hline Hebrew & 90 & Marathi & 1 \\
\hline
\end{tabular}




\begin{tabular}{llll}
\hline \hline Language & Freq. & Language & Freq. \\
\hline Min Nan & 4 & Tsonga & 2 \\
Mohawk & 1 & Turkish & 28 \\
Navajo & 1 & Turkish Sign & 1 \\
Nepali & 1 & Ukranian & 2 \\
Ngas & 1 & Urdu & 2 \\
Norwegian & 17 & Warlpiri & 4 \\
Nungon & 1 & Warlpiri (Light) & 2 \\
Polish & 25 & Welsh & 5 \\
Portuguese & 25 & Wichi & 1 \\
Punjabi & 1 & Wolof & 2 \\
Quebec Sign Language & 1 & Xhosa & 1 \\
Réunion Creole & 1 & Yucatec & 2 \\
Romanian & 4 & Zulu & 1 \\
Russian & 35 & & \\
Samoan & 2 & \\
Serbo-Croatian & 12 & & \\
Sesotho & 6 & & \\
Setswana & 1 & & \\
Signing Exact English & 4 & & \\
Slovenian & 2 & \\
Southern Peruvian Quechua & 5 & \\
Spanish & 153 & \\
Swahili & 4 & \\
Swedish & 21 & \\
Tagalog & 8 & \\
Tamil & 10 & \\
Telugu & 1 & \\
Thai & 5 & \\
Tongan & 1 & \\
Trinidadian Creole English & & \\
\hline
\end{tabular}




\section{Appendix B}

Table B.1. Frequency distribution of articles published in child language journals from 1974 until 2020 based on the country of affiliation of the authors.

\begin{tabular}{|c|c|c|c|}
\hline Country & Freq. & Country & Freq. \\
\hline Argentina & 1 & Kuwait & 3 \\
\hline Australia & 123 & Lesotho & 1 \\
\hline Austria & 11 & Lithuania & 4 \\
\hline Bangladesh & 1 & Malta & 3 \\
\hline Belgium & 36 & Mexico & 8 \\
\hline Brazil & 8 & Nepal & 1 \\
\hline Bulgaria & 1 & Netherlands & 139 \\
\hline Canada & 293 & New Zealand & 18 \\
\hline Chile & 5 & Norway & 25 \\
\hline China & 45 & Peru & 2 \\
\hline China Hong Kong & 5 & Philippines & 2 \\
\hline Colombia & 1 & Poland & 15 \\
\hline Costa Rica & 1 & Portugal & 16 \\
\hline Croatia & 4 & Romania & 2 \\
\hline Cyprus & 7 & Russia & 12 \\
\hline Czechia & 4 & Serbia & 6 \\
\hline Denmark & 18 & Singapore & 7 \\
\hline Ecuador & 1 & Slovenia & 2 \\
\hline Estonia & 8 & South Africa & 6 \\
\hline Finland & 30 & South Korea & 19 \\
\hline France & 139 & Spain & 54 \\
\hline Germany & 152 & Sweden & 20 \\
\hline Greece & 16 & Switzerland & 41 \\
\hline Hungary & 6 & Taiwan & 16 \\
\hline Iceland & 1 & Thailand & 2 \\
\hline India & 4 & Trinidad and Tobago & 3 \\
\hline Iran & 3 & Turkey & 15 \\
\hline Ireland & 17 & United Arab Emirates & 1 \\
\hline Israel & 103 & United Kingdom & 446 \\
\hline Italy & 110 & United States & 1436 \\
\hline Japan & 52 & Venezuela & 2 \\
\hline Kenya & 2 & & \\
\hline
\end{tabular}

